Article

\title{
Biological Control of Verticillium Wilt on Olive Trees by the Salt-Tolerant Strain Bacillus velezensis XT1
}

\author{
David Castro ${ }^{1}$, Marta Torres ${ }^{2,3, *}$, Inmaculada Sampedro ${ }^{2,3} \mathbb{C}^{-}$, Fernando Martínez-Checa ${ }^{2,3}{ }^{-}$, \\ Borja Torres ${ }^{1}$ and Victoria Béjar ${ }^{2,3}$ (I) \\ 1 Xtrem Biotech S.L., European Business Innovation Center, 18100 Granada, Spain; \\ dcastro@xtrembiotech.com (D.C.); btorres@xtrembiotech.com (B.T.) \\ 2 Department of Microbiology, Faculty of Pharmacy, University of Granada, 18071 Granada, Spain; \\ isampedro@ugr.es (I.S.); fmcheca@ugr.es (F.M.-C.); vbejar@ugr.es (V.B.) \\ 3 Biomedical Research Center, Institute of Biotechnology, 18016 Granada, Spain \\ * Correspondence: mtorres@ugr.es
}

Received: 1 June 2020; Accepted: 17 July 2020; Published: 20 July 2020

\begin{abstract}
Verticillium wilt, caused by the pathogen Verticillium dahliae, is extremely devastating to olive trees (Olea europea). Currently, no successful control measure is available against it. The objective of this work was to evaluate the antifungal activity of Bacillus velezensis XT1, a well-characterized salt-tolerant biocontrol strain, against the highly virulent defoliating V. dahliae V024. In vitro, strain XT1 showed to reduce fungal mycelium from 34 to $100 \%$, depending on if the assay was conducted with the supernatant, volatile compounds, lipopeptides or whole bacterial culture. In preventive treatments, when applied directly on young olive trees, it reduced Verticillium incidence rate and percentage of severity by 54 and $\sim 80 \%$, respectively. It increased polyphenol oxidase (PPO) activity by $395 \%$, indicating an enhancement of disease resistance in plant tissues, and it decreased by $20.2 \%$ the number of fungal microsclerotia in soil. In adult infected trees, palliative inoculation of strain XT1 in the soil resulted in a reduction in Verticillium symptom severity by $\sim 63 \%$. Strain XT1 is biosafe, stable in soil and able to colonize olive roots endophytically. All the traits described above make B. velezensis XT1 a promising alternative to be used in agriculture for the management of Verticillium wilt.
\end{abstract}

Keywords: biocontrol; antifungal activity; crop protection; Bacillus velezensis; Verticillium dahliae; Olea europaea

\section{Introduction}

Verticillium wilt, caused by V. dahliae, is a soil-borne fungal disease. First described in Italy [1], it affects around 400 plant species, ranging from herbaceous annuals to woody perennials, such as cotton, tomato, alfalfa, almond, pistachio, and peach [2,3]. Monocotyledonous plants are not affected, although they may act as asymptomatic reservoirs of the fungi [4], and only dicotyledonous plants can be attacked by the disease. Amongst the latter, $V$. dahliae is extremely devastating to olive trees (Olea europaea) and is currently considered the main soil-borne disease threatening olive production. Infection by Verticillium not only affects the volume of production, but also the quality and properties of the oil produced [5]. It affects all the olive-growing regions around the world, especially the Mediterranean area [6,7], and causes severe economic losses due to plant death [6]. Notably, Verticillium wilt is a serious threat to the olive industry in Spain, the world's largest producer of olive oil by volume with more than half of world production [8]. In particular, the disease is a major concern in the Andalusia region of southern Spain, which produces $83 \%$ of total olive oil in Spain [9]. In this region, the mean disease incidence is $20.4 \%$ [10], although this percentage could be underestimated due to the absence of more recent data. 
In its life cycle, $V$. dahliae [11] forms conidiospores and microsclerotia as resistant structures. The latter are darkly melanized mycelial cells which can persist in soil and dead material for more than 10 years, being the primary long-term survival structures. Once they germinate, the hyphae are attracted to the plant rhizosphere by a nutrient gradient and coat the plant roots [12]. Both the hyphae and the conidiospores can invade the healthy and damaged plant tissues and colonize the plant vascular system very rapidly [13]. As a result, water and nutrient balance are altered and the typical symptoms of Verticillium wilt, such as chlorosis or defoliation, appear [14].

Nowadays, no successful control measure of Verticillium wilt is available. The control of the disease is primarily done by preventive before-planting measures. These include the protection of plant material from $V$. dahliae infection during plant propagation and/or at transplanting using antagonistic biocontrol agents $[11,15,16]$. Disease management is hindered by the absence of effective fungicides, which are ineffective once the fungus has reached the plant vascular system, and the restriction of preventive chemical fumigants [17]. This, together with the demand of the society to render the agriculture industry more sustainable while maintaining a healthy environment, is pushing to search new strategies to grow crops with reduced agrochemicals, for instance using biological control agents as an alternative.

Biological control (or biocontrol) agents are microorganisms which colonize the plant rhizosphere and/or phylosphere, control pathogens, and act as fertilizers by several mechanisms [18,19]. Examples of these mechanisms are competition for ecological niches or production of volatile compounds and lipopeptide biosurfactants, which improve plant health by diminishing root-colonizing phytopathogens [20,21]. A number of these mechanisms lead to an increase in plant resistance to infections, known as induced systemic resistance [22]. Some of the desirable characteristics looked for in bacteria to be used as biocontrol tools against Verticillium are the reduction in the survival or germination of microsclerotia, the colonization of the host plant, the competition with the pathogen or the induction of resistance responses in the plant. Such characteristics should be evaluated in conditions which are similar to the field situation, in order to increase the chance of successful use in practice [23].

To date, selected isolates of several fungal species have been described as biological control agents against Verticillium. For instance, Trichoderma asperellum [24] and Fusarium oxysporum [25] have been identified as potential tools to fight Verticillium wilt. Concerning bacterial biocontrol agents, Serratia plymuthica [26], Paenibacillus alvei [27], and Pseudomonas fluorescens [28] have proved to be effective against $V$. dahliae in plant experiments. Regarding the members of the genus Bacillus, frequently used in agricultural systems as biocontrol tools, B. subtilis [29] and B. velezensis [30] have recently been reported to successfully reduce Verticillium wilt in planta. However, none of the biocontrol agents previously described have been isolated from saline environments. Soil salinization is a problematic issue that reduces agricultural productivity and is exacerbating with climate change. In recent years, it has been shown that salinity increases plant colonization and disease severity by $V$. dahliae [31,32] and reduces the activity of some Verticillium biocontrol agents [33]. Therefore, application of salt-tolerant biocontrol and plant growth promotion microorganisms seems to be a promising strategy to fight Verticillium wilt.

The objective of this study was to assess the antifungal activity of $B$. velezensis XT1, a well-characterized salt-tolerant biocontrol strain previously isolated in Andalusia (Spain) [34], against the fungal pathogen $V$. dahliae V024, a defoliating pathotype characterized as highly virulent [35]. The preventive and palliative application of B. velezensis XT1 on olive trees affected by Verticillium wilt was evaluated initially under non-saline conditions in greenhouse and field experiments.

\section{Materials and Methods}

\subsection{Strains and Routine Culture Conditions}

B. velezensis XT1 (CECT 8661) was grown in tryptic soy broth (TSB) at $30^{\circ} \mathrm{C}$ and 100 -rpm rotary shaking and maintained on tryptic soy agar (TSA). The reference strains Escherichia coli MC4100 
(CGSC 6152), E. coli OP50 (Carolina Biological, Burlington, USA), Pseudomonas aeruginosa PAO1 (CECT 4122), Pseudomonas putida KT2440 (ATCC 47054), and Burkholderia cepacia CC-Al74 (provided by the Department of Microbiology at the University of Granada, Spain) were also grown in TSB at $30^{\circ} \mathrm{C}$ and 100-rpm rotary shaking and maintained on TSA. Aliivibrio (formerly Vibrio) fischeri NRRL B-11177 (ATCC 49387) was grown in marine broth (MB) at $30{ }^{\circ} \mathrm{C}$ and $100-r p m$ rotary shaking. V. dahliae V024, obtained from the collection of the Department of Agronomy at the University of Córdoba (Spain), was cultivated in potato dextrose broth (PDB) at $25{ }^{\circ} \mathrm{C}$ with 100 -rpm rotary shaking and maintained on potato dextrose agar (PDA). Caenorhabditis elegans was maintained in nematode growth media (NGM) [36].

\subsection{Evaluation of the Toxicity of B. velezensis XT1}

The biosafety of B. velezensis XT1 was evaluated with a set of experiments [37] to assess its potential impact on microbial viability (E. coli MC4100 sensitivity test), microbial metabolism (Microtox assay in A. fischeri NRRL B-11177), and on the survival of soil nematodes (C. elegans N2 bioassay).

\subsubsection{E. coli MC4100 Sensitivity Assay}

The effect of B. velezensis XT1 on the survival of E. coli MC4100 was evaluated according to reference [37]. Briefly, $500 \mu \mathrm{L}$ of the filtered supernatant of an overnight culture of strain XT1 in TSB $\left(10^{8} \mathrm{CFU} \mathrm{mL}{ }^{-1}\right)$ were mixed with the same volume of a suspension of E. coli $\mathrm{MC} 4100\left(10^{9} \mathrm{CFU} \mathrm{mL}^{-1}\right)$ in $\mathrm{M} 9$ buffer $\left(3 \mathrm{~g} \mathrm{~L}^{-1} \mathrm{KH}_{2} \mathrm{PO}_{4}, 6 \mathrm{~g} \mathrm{~L}^{-1} \mathrm{Na}_{2} \mathrm{HPO}_{4}, 5 \mathrm{~g} \mathrm{~L}^{-1} \mathrm{NaCl}\right.$, and $1 \mathrm{~mL} \mathrm{~L}^{-1} \mathrm{MgSO}_{4}$ 1M; final pH 7.2) and incubated $1.5 \mathrm{~h}$ at $25^{\circ} \mathrm{C}$. The mixtures were spread on TSA plates to estimate E. coli CFU mL ${ }^{-1}$. The filtered supernatants of overnight cultures $\left(10^{8} \mathrm{CFU} \mathrm{mL}^{-1}\right)$ of two biocontrol strains proposed in the literature, P. putida KT2440 and B. cepacia CC-Al74, and 0.2\% (w/v) copper sulfate, widely used in agriculture, were used for comparison. Non-inoculated TSB was used as a control. The assay was conducted in triplicate.

\subsubsection{A. fischeri NRRL B-11177 Microbial Metabolism Evaluation}

Microbial metabolism assays were performed according to Johnson (2005) [38] using the supernatant of a 48 -h culture of $B$. velezensis XT1 $\left(10^{8} \mathrm{CFU} \mathrm{mL}{ }^{-1}\right)$ in Cooper medium [39]. The assay was conducted with the bioluminescent $A$. fischeri NRRL B-11177 $\left(10^{8} \mathrm{CFU} \mathrm{mL}^{-1}\right)$ using a Microtox 500 luminescence analyzer (Instrumentación Analítica S.A., Madrid, Spain). Toxicity was expressed as the concentration of B. velezensis XT1 supernatant that reduced $50 \%$ (EC50) of the initial luminescence of $A$. fischeri after $15 \mathrm{~min}$ exposure [40]. Non-inoculated Cooper medium was used as a control. The assay was conducted in triplicate.

\subsubsection{C. elegans N2 Pathogenicity Assay}

The impact of $B$. velezensis XT1 on the survival and viability of soil nematodes was evaluated on the C. elegans N2 model organism. The assay was conducted according to Darby et al. [41], with the modifications described by Navas et al. [42]. Briefly, $20 \mu \mathrm{L}$ of an overnight culture of strain XT1 in TSB $\left(10^{8} \mathrm{CFU} \mathrm{mL}^{-1}\right)$ were spread on NGM [36] and incubated $24 \mathrm{~h}$ at $30^{\circ} \mathrm{C}$. Then, five adult larvae were added to each plate. P. aeruginosa PAO1, a pathogenic strain that causes the death of the nematode [43], was used for comparison. E. coli OP50 [44] was used as a control. The volume and concentration $\left(10^{8} \mathrm{CFU} \mathrm{mL} \mathrm{mL}^{-1}\right)$ as with strain XT1 were used in the case of P. aeruginosa PAO1 and E. coli OP50. Plates were incubated at $24^{\circ} \mathrm{C}$ for 8 days. The nematodes were examined at 20X magnification and the number of alive individuals was recorded every day. Five replicates were conducted.

The C. elegans model was also used to determine the concentration of strain XT1 that was lethal to $50 \%$ of the individuals (LC50). The assay was conducted according to Williams and Dusenbery [45]. Briefly, ten adult larvae were transferred with a needle to each well of a 48-well culture plate, filled with $50 \mu \mathrm{L}$ of a culture of E. coli OP50 $\left(10^{9} \mathrm{CFU} \mathrm{mL}^{-1}\right)$ and $500 \mu \mathrm{L}$ of $\mathrm{K}+$ medium [46]. The supernatant of a culture of strain XT1 $\left(10^{8} \mathrm{CFU} \mathrm{mL}^{-1}\right)$ in Schaeffer's-glucose (SG) medium [47] was diluted 1/2, 1/4, 
$1 / 8$, and $1 / 50$ in liquid NGM and added to the wells up to $1 \mathrm{~mL}$ final volume. Plates were incubated at $20^{\circ} \mathrm{C}$ for $24 \mathrm{~h}$. The nematodes were examined at $20 \times$ magnification and the number of alive individuals was recorded. Copper sulfate, commonly used in agriculture as a fungicide, was used at final concentrations of $0.2 \%(w / v)$ for comparison, and non-treated wells were used as controls. The assay was repeated twice.

\subsection{In Vitro Evaluation of the Antifungal Activity of B. velezensis XT1}

The antifungal activity of the whole culture, supernatant, crude lipopeptide extract, and volatile compounds produced by $B$. velezensis XT1 were tested in five different types of assays against V. dahliae V024.

\subsubsection{Assay in Liquid Media}

Inhibition of fungal conidiospore germination (and posterior mycelium formation) was evaluated using the supernatant of a liquid culture of strain XT1 [48,49]. Briefly, a 7-day culture of $V$. dahliae was crushed and filtered through an $80-\mu \mathrm{m}$ pore gauze. This conidiospore suspension was adjusted to a concentration of $10^{7}$ conidiospores $\mathrm{mL}^{-1}$, and was treated with $2.5 \mu \mathrm{g} \mathrm{mL} \mathrm{m}^{-1}$ benzylpenicillin and $10 \mu \mathrm{g} \mathrm{mL}{ }^{-1}$ streptomycin to avoid bacterial contamination. Strain XT1 was cultivated in nutritive broth (NB) for $72 \mathrm{~h}$ at $30^{\circ} \mathrm{C}\left(10^{8} \mathrm{CFU} \mathrm{mL}{ }^{-1}\right)$ with 100-rpm rotary shaking. The culture was centrifuged at $12,000 \times \mathrm{g}$ for 15 minutes and the supernatant was filtered through a $0.22 \mu \mathrm{m}$-pore membrane filter. A mix of $900 \mu \mathrm{L}$ of $V$. dahliae conidiospore suspension and $300 \mu \mathrm{L}$ of the filtered supernatant of strain XT1 were placed in the wells of a 48-well culture plate. The same volume of conidiospore suspension supplemented with $50 \mu \mathrm{g} \mathrm{mL}^{-1}$ cycloheximide was used as a control for fungal growth inhibition, while the conidiospore suspension alone was used as a control for fungal growth. After 30 days of incubation at $25^{\circ} \mathrm{C}$ with 100-rpm rotary shaking, the growth of the pathogenic fungi was assessed visually. Assays were carried out in triplicate.

\subsubsection{Assay on Solid Media}

Mycelium inhibition was measured on solid medium as described by Ji et al. [50] following the modifications by Torres et al. [34]. Ten microliters of an overnight culture of XT1 in TSB $\left(10^{8} \mathrm{CFU} \mathrm{mL} \mathrm{mL}^{-1}\right)$ were point-inoculated on the surface of a PDA plate. Then, a 4-mm agar plug of $V$. dahliae mycelium was deposited on the opposite side of the plate. After 20 days of incubation at $25^{\circ} \mathrm{C}$, the mycelium inhibition rate $[\mathrm{IR} \%=(\mathrm{A}-\mathrm{B}) / \mathrm{A} \times 100]$ was calculated, considering $\mathrm{A}$ as the maximum and $\mathrm{B}$ the minimum values of the mycelium radius. Non-inoculated TSB was used as a control. The assay was conducted in triplicate.

\subsubsection{Assay on Modified Solid Media}

A modified solid medium was prepared using the supernatant of B. velezensis XT1 instead of distilled water to prepare PDA plates. Briefly, a 3-day culture $\left(10^{8} \mathrm{CFU} \mathrm{mL}{ }^{-1}\right)$ of strain XT1 in optimal medium for lipopeptide production (MOLP) [51] was centrifuged at $5000 \times \mathrm{g}$ for $5 \mathrm{~min}$ and filtered through a $0.22 \mu \mathrm{m}$ pore-size membrane filter. The filtered supernatant was used undiluted and diluted to half (with distilled water) to hydrate the PDA powder. Then, $\mathrm{pH}$ was adjusted to 5.6 \pm 0.2 and the medium was sterilized. Once the modified solid media were ready, a 4-mm plug of $V$. dahliae mycelium was placed in the center of the plates, which were incubated for 20 days at $25^{\circ} \mathrm{C}$. The control consisted of PDA hydrated with distilled water alone. The percentage of mycelium inhibition was calculated by image analysis using ImageJ software [52], measuring the area of fungal growth and comparing it to the control. Three replicates were conducted. 


\subsubsection{Volatile Compounds Antifungal Test}

The effect of volatile compounds produced by B. velezensis XT1 on $V$. dahliae was tested on bipartite petri dishes. A 4-mm plug of $V$. dahliae mycelium was placed on one half of the dish, containing PDA. On the other half, containing MOLP, $10 \mu \mathrm{L}$ of an overnight culture of XT1 in TSB $\left(10^{8} \mathrm{CFU} \mathrm{mL}^{-1}\right)$ were point-inoculated on the surface of the medium. Non-inoculated TSB was used as a control. Plates were sealed and incubated for 15 days at $25^{\circ} \mathrm{C}$. Fungal growth was assessed by image analysis using ImageJ software. The assay was repeated three times.

\subsubsection{Crude Lipopeptide Extract Antifungal Test}

The effect of the lipopeptides produced by $B$. velezensis XT1 on fungal conidiospore germination and mycelium formation was evaluated using a crude lipopeptide extract of strain XT1 instead of water to prepare the medium. The lipopeptides produced by strain XT1 were previously identified as four different types of surfactin, three bacillomycins D and fengycin A and B [49]. Briefly, lipopeptides were extracted from a 3-day culture of strain XT1 on MOLP $\left(10^{8} \mathrm{CFU} \mathrm{mL}{ }^{-1}\right)$, according to Yazgan et al. [53]. The culture supernatant of strain XT1 was subjected to three organic extractions with one volume $n$-butanol, with the aid of a decantation funnel. The lipopeptide was dried, evaporating the organic phase with a vacuum concentrator, and dissolved in distilled water. This solution was used to hydrate the PDA powder. Then, $\mathrm{pH}$ was adjusted to $5.6 \pm 0.2$ and the medium was sterilized. Medium was prepared with final crude lipopeptide extract concentrations of 10 and $20 \mathrm{mg} \mathrm{mL}^{-1}$. After this, a 4-mm plug of $V$. dahliae mycelium was placed in the center of the plates, which were incubated at $25^{\circ} \mathrm{C}$ for 20 days. The control consisted of PDA prepared with distilled water. The percentage of mycelium inhibition was calculated using the ImageJ software. Three replicates were conducted.

The minimal inhibitory concentration (MIC) of the crude lipopeptide extract of strain XT1, defined as the lowest concentration that totally inhibits fungal growth, was also determined. Briefly, a mix of $900 \mu \mathrm{L}$ of $V$. dahliae conidiospore suspension, obtained as explained above, and $300 \mu \mathrm{L}$ of strain XT1 crude lipopeptide extract were placed in the wells of a 48-well culture plate. The final concentrations of lipopeptide in the wells were $0.5,1,2,4,6,8,10$, and $20 \mathrm{mg} \mathrm{mL}^{-1}$. The same controls as in Section 2.3.1 were used. The growth of the $V$. dahliae was assessed visually after 30 days of incubation at $25^{\circ} \mathrm{C}$ with 100-rpm rotary shaking. The experiment was carried out in triplicate.

\subsection{Preventive Activity by B. velezensis XT1 of Verticillium Wilt on Olive Trees}

B. velezensis XT1 was evaluated as a protective or preventive tool for the management of the Verticillium wilt disease on olive trees. Forty-eight young ( $\sim 9$-month old) olive trees (O. europaea cv. Picual) in 1.2-L pots filled with non-sterile potting soil (Compo Sana universal substrate, Compo, Münster, Germany) were used. The plants were divided in two separate replicates, each with 24 trees. They were placed randomly in a greenhouse in Andalusia (Spain) at $25 / 20^{\circ} \mathrm{C}$ (day/night), relative humidity $60-80 \%$, long-day photoperiod (16:8 h light:dark), luminosity of $250 \mu \mathrm{S} \mathrm{cm}^{-2} \mathrm{~s}^{-1}$, and drip irrigation systems ( $\sim 50 \mathrm{~mL}$ per day). The experiment lasted 3 months. Briefly, 11 and 3 days before pathogen inoculation, plants were bacterized with $B$. velezensis $\mathrm{XT} 1$ as follows. The inoculation was conducted directly in the soil, at $2 \mathrm{~cm}$ from the plant stem, with $1 \mathrm{~mL}$ of a 5-day culture of strain XT1 in SG $\left(10^{9} \mathrm{CFU} \mathrm{mL} \mathrm{mL}^{-1}\right)$. Then, following the methods of Colella et al. [54] and Trapero et al. [55], the plants were uprooted, washed in running water, and infected with a conidiospore suspension of $V$. dahliae by root immersion for $10 \mathrm{~min}$, and later, changed to new pots with fresh non-sterile potting soil. The conidiospore suspension of $V$. dahliae was obtained with a 7-day culture of the fungus, which was crushed and filtered through an $80-\mu \mathrm{m}$ pore gauze and adjusted to a concentration of $10^{7}$ conidiospores $\mathrm{mL}^{-1}$. Three and 11 days after the infection, the group of treated plants was inoculated again with $B$. velezensis XT1 as explained above. Control of each replicate consisted of 12 infected non-treated olive trees. 
The presence of $V$. dahliae on olive tree leaves was determined by PCR 30 and 90 days after fungal infection. Briefly, total DNA from $5 \mathrm{~g}$ of a pool of $\sim 30$ olive tree leaves of each condition and replicate was purified using the methodology described by Doyle and Doyle [56]. Detection of Verticillium was done using the specific primers DB19Fwd 5'-CGGTGACATAATACTGAGAG-3' and DB22Rev 5'-GACGATGCGGATTGAACGAA-3', which amplify specific polymorphic DNA bands of 539-bp in defoliating $V$. dahliae isolates [57].

Polyphenol oxidase (PPO) activity was measured to evaluate the stress caused by the infection 30 days after the inoculation of the plants with $V$. dahliae. Briefly, $5 \mathrm{~g}$ of a pool of 30 olive tree leaves of each condition and replicate were homogenized with $0.6 \mathrm{~g}$ of polyvinylpolypyrrolidone and $20 \mathrm{~mL}$ of a buffer solution containing $\mathrm{NaH}_{2} \mathrm{PO}_{4} \times 2 \mathrm{H}_{2} \mathrm{O} 0.07 \%(w / v)$ and $1.6 \%(w / v) \mathrm{Na}_{2} \mathrm{HPO}_{4} \times 12 \mathrm{H}_{2} \mathrm{O}$. After $2 \mathrm{~min}$, the mixture was filtered through paper and centrifuged at $10,000 \times \mathrm{g}$ for $15 \mathrm{~min}$ at $4{ }^{\circ} \mathrm{C}$. One-hundred $\mu \mathrm{L}$ of the supernatant were combined with $2.8 \mathrm{~mL}$ phosphate buffer $0.2 \mathrm{mM} \mathrm{pH} 7$ and $50 \mu \mathrm{L}$ catechol $60 \mathrm{mM}$. The mix was maintained at $25^{\circ} \mathrm{C}$ and the variation in absorbance was measured at $420 \mathrm{~nm}$ for $3 \mathrm{~min}$. PPO activity was expressed as the change in the absorbance unit per second per gram of plant fresh weight [58]. Leaves of infected non-treated olive trees were used as the control.

The degree of plant infection and the number of microsclerotia in the soil were determined 90 days after the inoculation with $V$. dahliae. The first was assessed determining the incidence rate and the percentage of severity. The incidence rate referred to the percentage of plants visually affected (by chlorosis, leaf and shoot necrosis or defoliation) in each treatment. The percentage of severity, measured as the relative area under the disease progress curve (AUDPC), was determined according to López-Escudero et al. [59]. Regarding the number of microsclerotia in the soil, this was assessed according to Kabir et al. [60]. Briefly, a sample of $5 \mathrm{~g}$ of soil of each pot was taken $(\sim 3 \mathrm{~cm}$ from the plant stem, at $\sim 10$-cm depth), homogenized with a mortar, and dried at $37^{\circ} \mathrm{C}$ for 2 days. Then, the powder was transferred to a tube with $2.5 \mathrm{~mL}$ of a solution of $7.5 \mathrm{mg} \mathrm{mL}^{-1}$ methionine in order to break fungistasis and improve detection [61], and was incubated with an open lid at $30^{\circ} \mathrm{C}$ for 3 days. The resulting dry powder was grinded up again and placed over Sorensen's NP10 medium [60] supplemented with $50 \mu \mathrm{g} \mathrm{mL} \mathrm{m}^{-1}$ chloramphenicol and $10 \mu \mathrm{g} \mathrm{mL} \mathrm{m}^{-1}$ streptomycin. After incubation at $20^{\circ} \mathrm{C}$ for 15 days in the absence of light, the surface of the medium was washed with sterile distilled water and the number of microsclerotia was quantified at 10X magnification. The control consisted of potting soil from infected non-treated olive trees.

\subsection{Field Experiments with B. velezensis XT1 on Olive Trees Diseased by V. dahliae}

B. velezensis XT1 was tested as a palliative treatment on twenty adult ( 10-year old) Picual olive trees that showed symptoms of affectation by $V$. dahliae. Plant infection was confirmed by isolating the pathogen from affected areas on PDA, observation by optical microscopy after safranin staining [62], and determination of the number of microsclerotia in the soil ( 15-cm depth) [60]. The trees were planted in the open field in a parcel in Granada, Spain $\left(37^{\circ} 25^{\prime} 17.4^{\prime \prime} \mathrm{N} 3^{\circ} 44^{\prime} 38.5^{\prime \prime} \mathrm{W}\right)$. The type of soil in the parcel corresponds to calcaric regosol, according to FAO [63]. Treated trees were inoculated with 20 $\mathrm{L}$ of a 5-day culture of $B$. velezensis XT1 in MOLP medium ( $10^{10} \mathrm{CFU}$ per olive tree), which was injected in the soil ( $\sim 40-\mathrm{cm}$ depth) in six points at $\sim 80 \mathrm{~cm}$ from the olive tree trunk. Ten diseased non-treated trees were used as control. Seven months after the inoculation, another application of $B$. velezensis XT1 was carried out, as explained before. Fourteen months after the first inoculation, the symptom severity of the olive trees was assessed using a $0-4$ rating scale according to the percentage of plant tissue affected, being $0=$ healthy plant or plant without symptoms, $1=$ affected plant in $1-33 \%, 2=$ $34-66 \%, 3=67-99 \%$, and $4=$ dead plant [59].

\subsection{Permanence of B. velezensis XT1 in Soil}

To study the permanence of the B. velezensis XT1 population in the soil after plant inoculation, a rifampicin-resistant $\left(\mathrm{Rif}^{\mathrm{R}}\right)$ XT1 derivative was used to facilitate selection. Briefly, to obtain this derivative, $5 \mathrm{~mL}$ of an overnight culture of strain XT1 in TSB $\left(10^{8} \mathrm{CFU} \mathrm{mL} \mathrm{mL}^{-1}\right)$ were centrifuged 
at $5,000 \times \mathrm{g}$ for $10 \mathrm{~min}$. After washing twice with $0.8 \% \mathrm{NaCl}(w / v)$, the pellet was dissolved in $400 \mu \mathrm{L}$ of the same saline solution. Then, $100 \mu \mathrm{L}$ were plated in each plate TSA supplemented with $100 \mu \mathrm{g} \mathrm{mL}-1$ rifampicin. After incubation at $30^{\circ} \mathrm{C}$ for 3 days, individual spontaneous rifampicin-resistant mutant colonies were selected.

For the assay, twenty 6-month old Picual olive trees were used. Trees were divided in two separate replicates, each with 10 plants. The olive trees were in 1.6-L pots with Compo Sana universal substrate (Compo, Münster, Germany). They were placed randomly in a greenhouse at 25/20 ${ }^{\circ} \mathrm{C}$ (day/night), relative humidity $60-80 \%$, long-day photoperiod (16:8 h light:dark), and luminosity of $250 \mu \mathrm{S} \mathrm{cm}^{-2} \mathrm{~s}^{-1}$. Then, B. velezensis XT1 Rif ${ }^{R}$ was cultured in MOLP for 2 days $\left(10^{8} \mathrm{CFU} \mathrm{mL}^{-1}\right)$ and applied directly in the soil $\left(10^{6} \mathrm{UFC}^{-1}\right.$ of substrate) of half the plants in each replicate. The control of each replicate consisted of five non-treated olive trees. All plants were watered every $24 \mathrm{~h}$ with a similar amount of water $(\sim 50 \mathrm{~mL})$ through a drip irrigation system. Bacterial count was determined 30, 60, 90, and 120 days after the experiment started. In brief, soil was homogenized with $0.8 \%(w / v) \mathrm{NaCl}$, and 10 -fold serial dilutions were prepared and plated on nutrient agar (NA) supplemented with $100 \mu \mathrm{g} \mathrm{mL}-1$ rifampicin and incubated for $48 \mathrm{~h}$ at $30{ }^{\circ} \mathrm{C}$ in order to estimate XT1 Rif ${ }^{\mathrm{R}} \mathrm{CFU} \mathrm{g}^{-1}$.

\subsection{Ability of B. velezensis XT1 to Colonize Endophytically Olive Roots}

The capacity of B. velezensis XT1 to grow endophytically in olive roots was evaluated as follows, using the olive tree plants of the previous experiment. After 120 days, the plants were extracted from the pots and the soil was discarded. The roots were cut and washed with sterile distilled water and ethanol 70\% $(v / v)$. Then, they were submerged in $\mathrm{NaClO} 5 \%(v / v)$ for $1.5 \mathrm{~min}$. After vortexing, the $\mathrm{NaClO}$ was discarded and the roots were washed three times with abundant sterile distilled water. Finally, they were cut into small pieces $(\sim 1 \mathrm{~cm})$ and homogenized with a mortar and pestle in $5 \mathrm{~mL} 0.8 \%$ $(w / v) \mathrm{NaCl}$. The control of each replicate consisted of roots from five non-treated olive trees. Bacterial count was determined on NA supplemented with $100 \mu \mathrm{g} \mathrm{mL} \mathrm{m}^{-1}$ rifampicin as previously explained.

\subsection{Statistical Analyses}

Statistical analyses were conducted using the R software [64]. Differences with the control in the experiments conducted were assessed by post hoc Tukey analysis. A normal distribution for measured variables, as well as a quasi-Poisson distribution and square root link function for the counted variables, were assumed.

\section{Results}

\subsection{Biosafety of B. velezensis XT1}

The safety of B. velezensis XT1 was evaluated using three types of tests. In the sensitivity assay, strain XT1 reduced the population of E. coli MC4100 (Figure 1a). This reduction, however, was significantly $(p<0.05)$ inferior to that of copper sulfate, usually used as a fungicide in agriculture, which completely inhibited the growth of E. coli MC4100 (Figure 1a). In the Microtox test, the impact of B. velezensis XT1 on the metabolism (luminescence) of $A$. fischeri NRRL B-11177 was evaluated. No significant reduction in luminescence was observed after $10 \mathrm{~min}$ of exposition. After $15 \mathrm{~min}$, the EC50 of strain XT1 was reached with a solution in distilled water, with $90 \%(v / v)$ of culture supernatant. Finally, the toxicity of $B$. velezensis XT1 was assessed using the nematode C. elegans N2. After 8 days of incubation, there were not significant differences between strain XT1 and the control E. coli OP50. The results obtained for P. aeruginosa PAO1, which caused a high mortality of the nematodes, were significantly different $(p<0.01)$ to the results obtained by strain XT1 and E. coli OP50 (Figure 1b). Regarding the LC50 value of B. velezensis XT1, it was found that the concentration used in the field as being effective $\left(2 \times 10^{6} \mathrm{CFU} \mathrm{g}^{-1}\right.$ soil) is nearly ten times smaller than its LC50, identified to be $1.8 \times 10^{7} \mathrm{CFU} \mathrm{g}^{-1}$. In the case of the chemical fungicide of agricultural use, copper sulfate, its average effective dose, $0.2 \%(w / v)$, was higher than its respective LC50, 0.03\% (w/v) (Figure 1c). In both cases, 
differences between LC50 and average concentration used in the field were found significant $(p<0.001)$. Mortality of nematodes was not observed in the non-treated control, and therefore a LC50 value was not calculated.

\section{a}

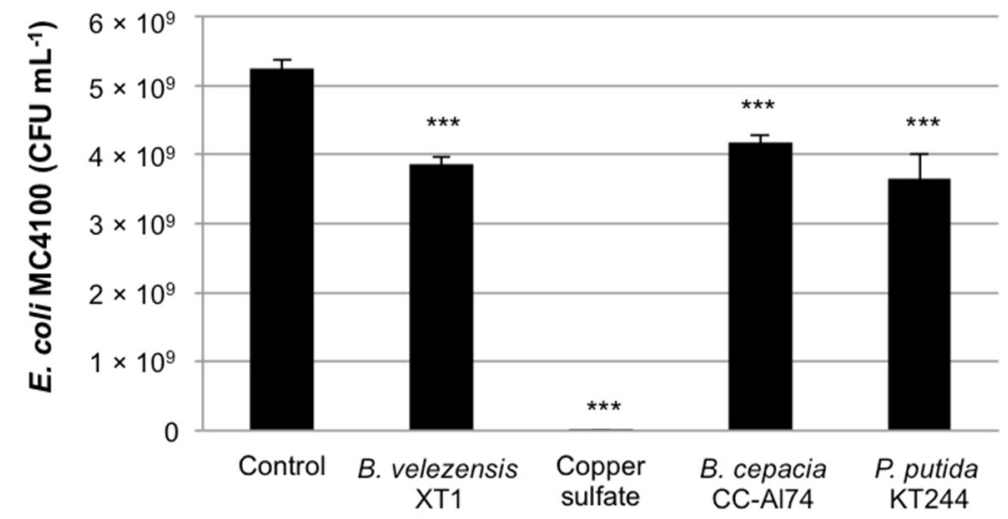

b

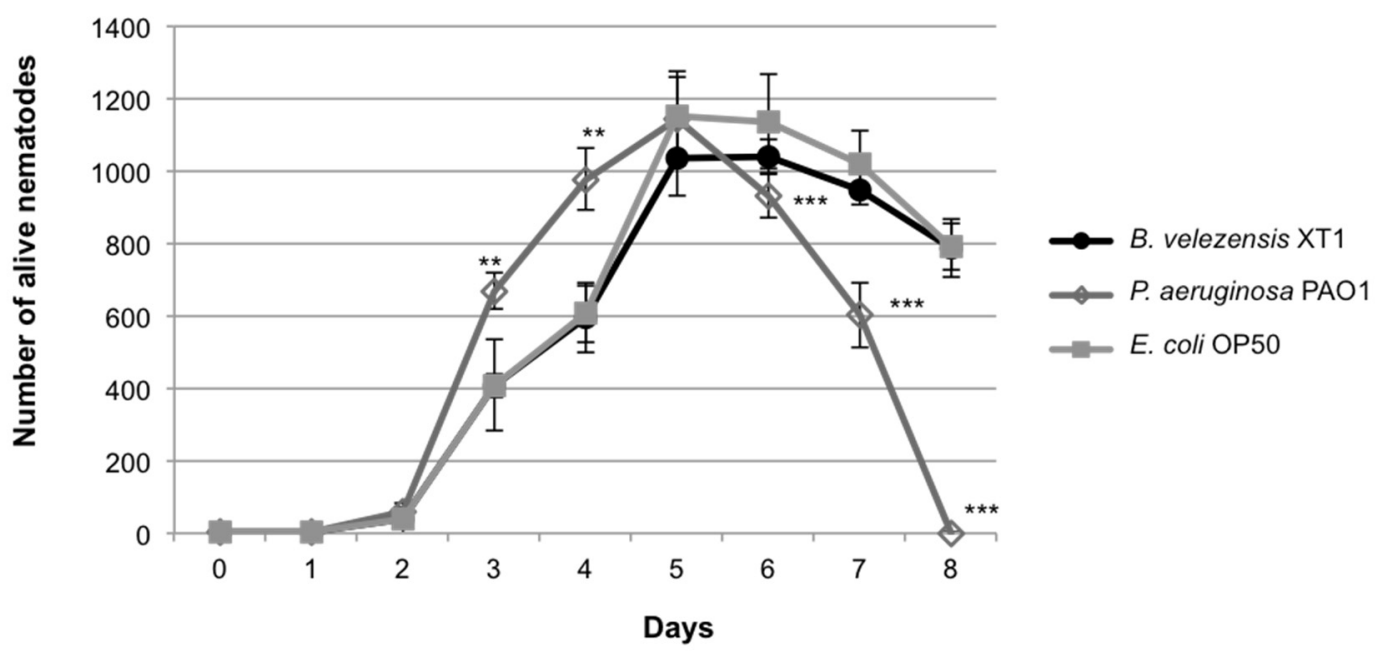

C
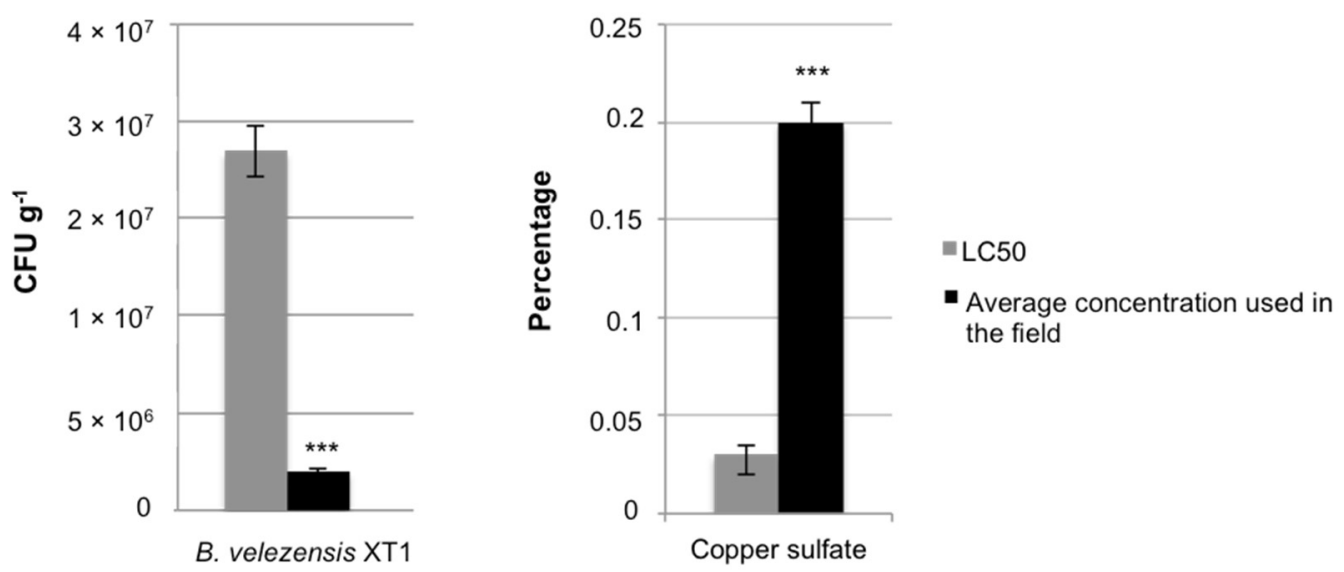

Figure 1. Biosafety evaluation of Bacillus velezensis XT1. (a) Escherichia coli MC4100 sensitivity assay. Pseudomonas putida KT2440, Burkholderia cepacia CC-A174 and $0.2 \%(w / v)$ copper sulfate were used for comparison. Non-inoculated tryptic soy broth (TSB) was used as a control. (b) Caenorhabditis elegans N2 pathogenicity test. Pseudomonas aeruginosa PAO1 was used for comparison. E. coli OP50 was used as a control. (c) Comparison of LC50 values obtained in C. elegans N2 and average concentrations used 
in the field. Copper sulfate was used for comparison. Significant differences between the LC50 and the field concentration are indicated by asterisks $\left(* * p<0.01{ }^{* * *}, p<0.001\right)$.

\subsection{In Vitro Antifungal Activity of B. Velezensis XT1}

The antifungal activity of $B$. velezensis XT1 against $V$. dahliae V024 was assessed in several types of experiments. In the liquid media assay, the supernatant of strain XT1 completely abolished (100\% inhibition) conidiospore germination and, therefore, later mycelium formation of $V$. dahliae after 30 days of incubation. The plate assay demonstrated that B. velezensis XT1 had an in vitro antagonistic effect and reduced by over $56 \%$ the mycelia of $V$. dahliae after 20 days of incubation (Figure $2 a$ ). In the modified plate assay using the undiluted and half-diluted supernatant of strain XT1 liquid culture, Verticillium mycelium was reduced by 94 and 91\%, respectively (Figure 2b). The volatile compounds of strain XT1 reduced the growth of $V$. dahliae by $34 \%$ (Figure 2c). Regarding the crude lipopeptide extract, it reduced the growth of the fungi by $80 \%$ and by $88 \%$ when used at a concentration of 10 and $20 \mathrm{mg} \mathrm{mL}^{-1}$, respectively (Figure $2 \mathrm{~d}$ ). In liquid medium, the MIC of the crude lipopeptide extract was determined to be at $20 \mathrm{mg} \mathrm{mL}^{-1}$ (Figure 2e). In all the assays, the differences with the respective controls were significantly different $(p<0.05)$.

a
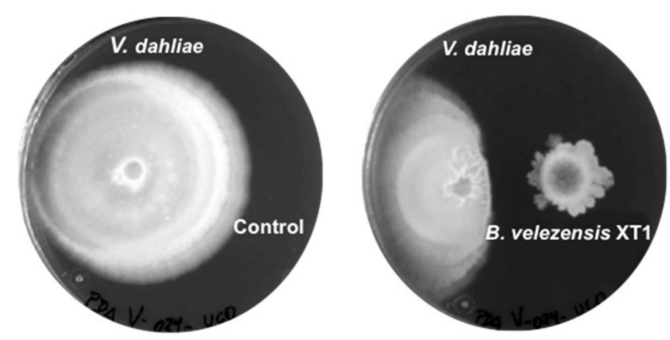

b
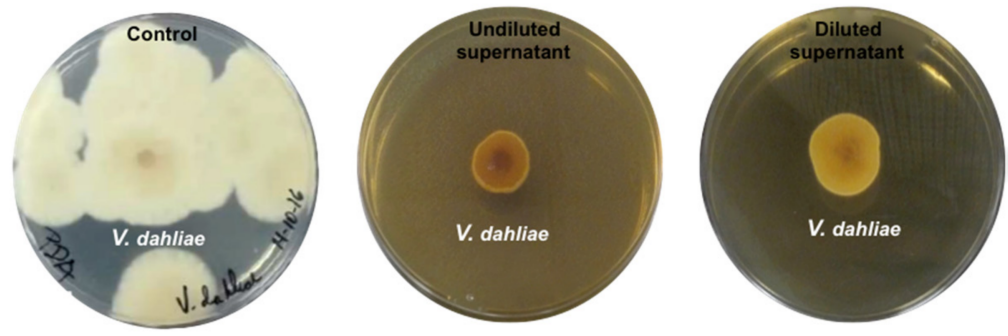

C
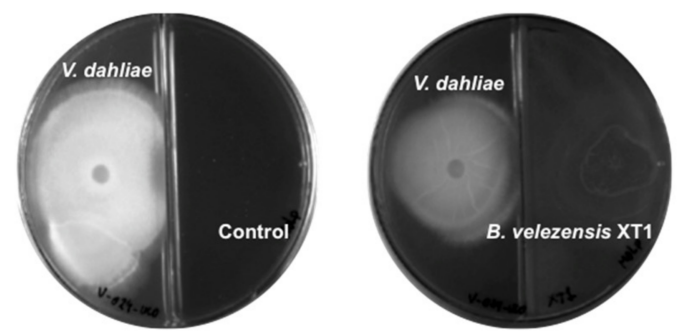

d
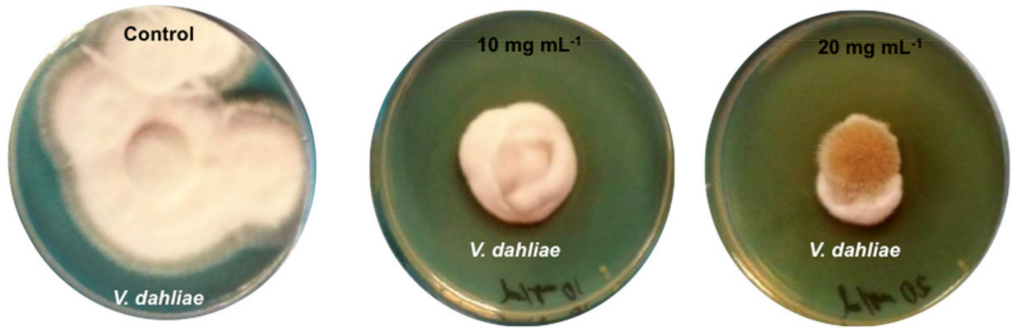

Figure 2. Cont. 


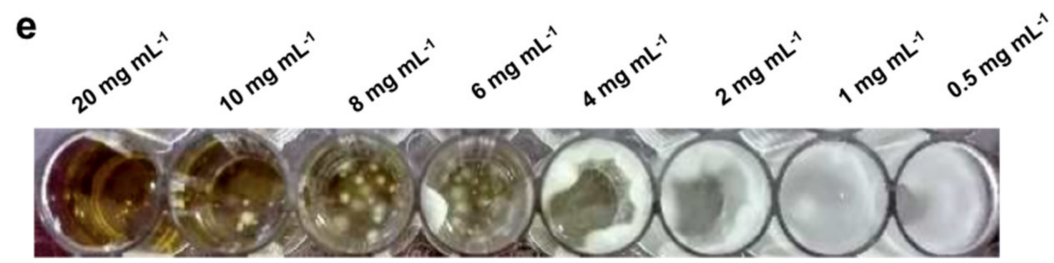

Figure 2. In vitro antifungal activity of Bacillus velezensis XT1 against Verticillium dahliae V024. (a) Assay on solid media with the whole culture of strain XT1. Non-inoculated tryptic soy broth (TSB) was used as a control. (b) Assay on modified medium prepared with the half-diluted and undiluted supernatant of strain XT1. Control consisted of medium hydrated with distilled water. (c) Volatile compounds antifungal test. Control consisted of non-inoculated TSB. (d) Crude lipopeptide extract antifungal test. Control consisted of medium hydrated with distilled water. (e) Minimal inhibitory concentration (MIC) of the crude lipopeptide extract determined in a liquid assay.

\subsection{Prevention of Verticillium Wilt on Olive Trees Treated with B. velezensis XT1}

The effect of the preventive treatment by $B$. velezensis XT1 on olive trees artificially infected with $V$. dahliae was estimated using young trees ( 9-month old). Thirty days after the infection of the olive trees with $V$. dahliae (i.e., 45 days after the first inoculation with strain XT1), no disease symptoms could be observed. The presence of the fungi was detected by PCR in the non XT1-treated olives, although no amplification was obtained in the olive trees which had been inoculated with $B$. velezensis XT1 (Figure 3a). Ninety days after the infection with $V$. dahliae, the fungus was detected by PCR also in the XT1-treated olives, although with a weak amplification (Figure 3a).

At the end of the experiment, the number of microsclerotia in the soil was significantly $(p \leq 0.05)$ diminished by $20.2 \%$ due to the application of B. velezensis XT1, more exactly, from 47.2 to 36.4 microsclerotia $\mathrm{g}^{-1}$ soil. PPO activity, measured to evaluate plant response to stress, was increased by $395 \%(p<0.05)$ in the XT1-treated plants in comparison to the control (Figure 3b).

Regarding the degree of infection of the trees, this was assessed determining the incidence rate and percentage of severity. The results show a significant $(p<0.05)$ reduction of $54 \%$ in the incidence rate (Figure 3c) and of $\sim 80 \%$ in the percentage of severity (Figure 3d) in the infected XT1-treated olive trees in comparison with the infected non-treated control trees. The differences could easily be observed at the branch (Figure 3e) and whole plant level (Figure 3f).

a

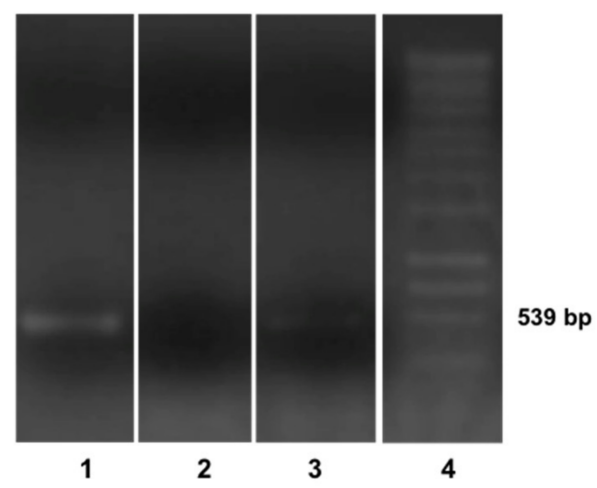

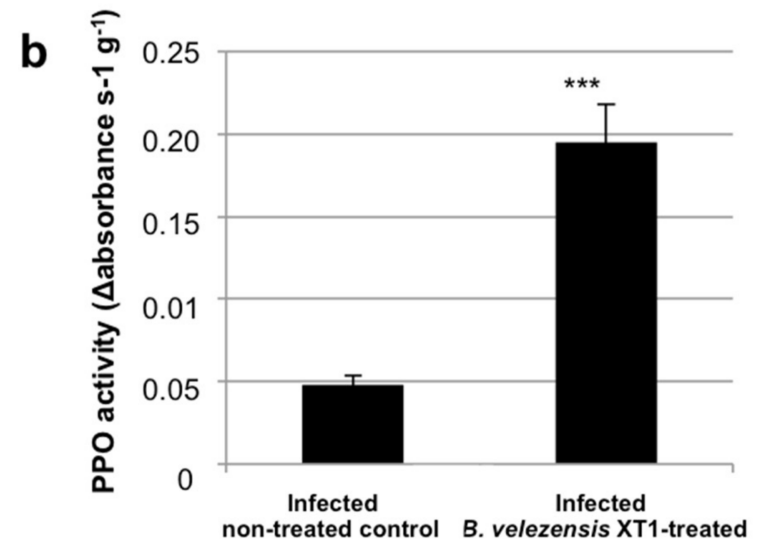

Figure 3. Cont. 


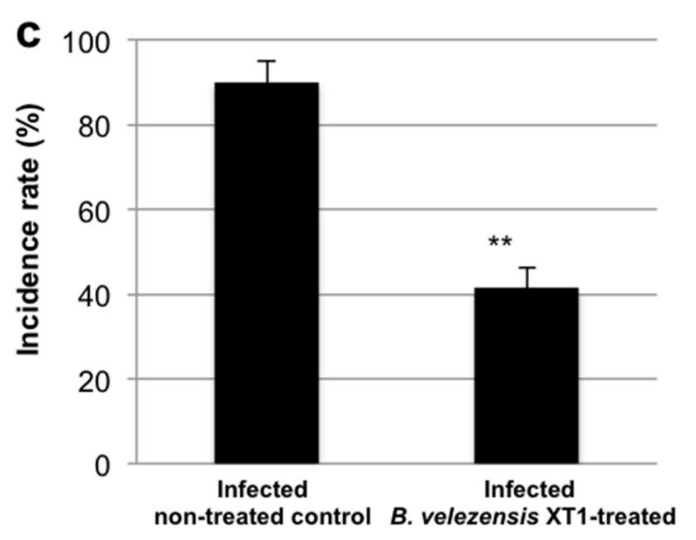

d

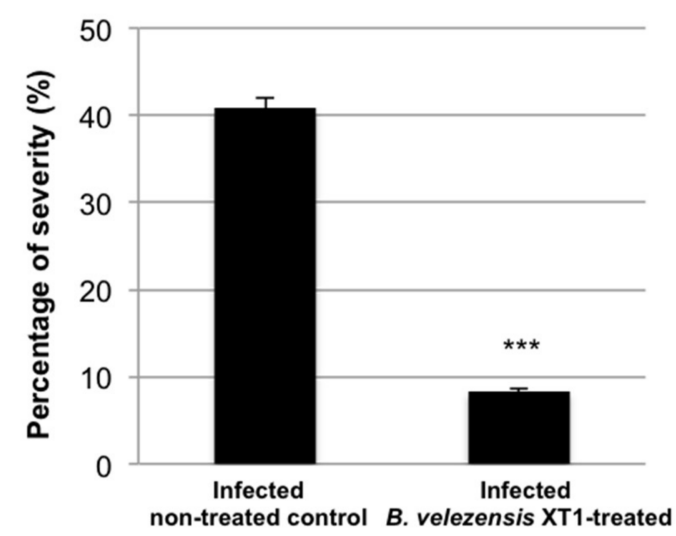

e

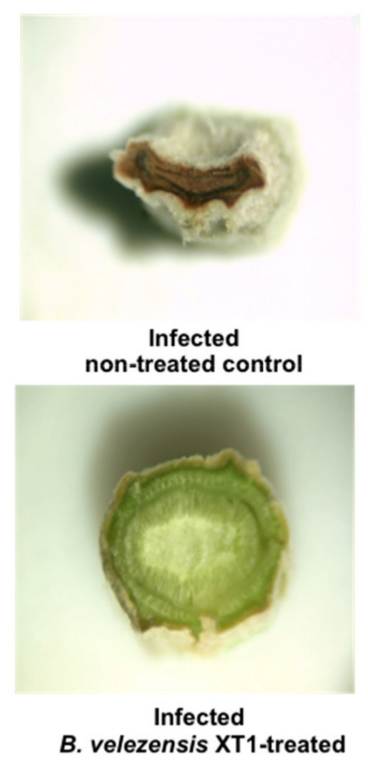

f

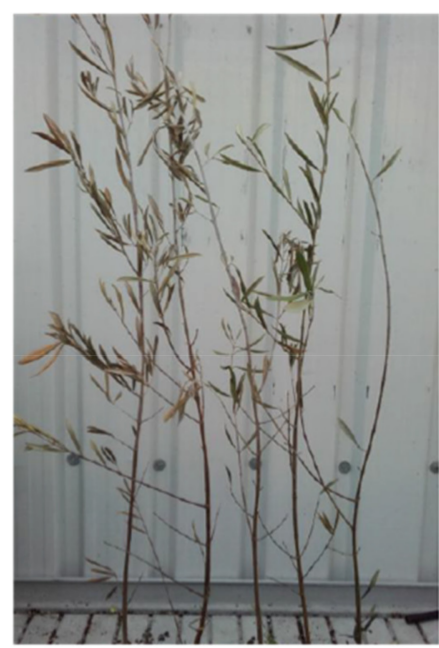

Infected

non-treated control

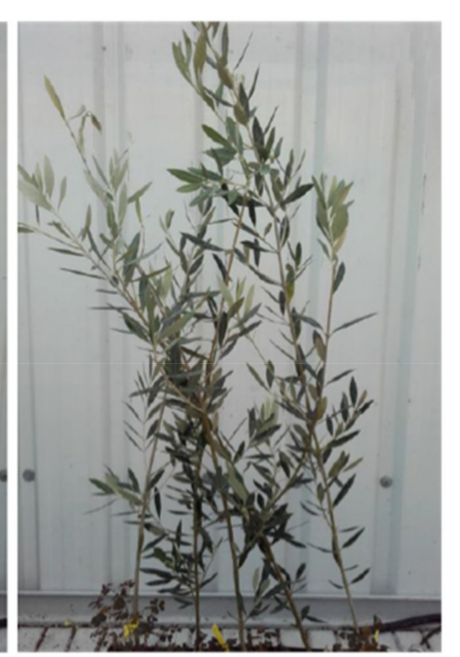

Infected

B. velezensis XT1-treated

Figure 3. Prevention of Verticillium wilt on young olive trees by Bacillus velezensis XT1. (a) PCR amplification of Verticillium dahliae in olive tree leaves. 1: Infected non-treated control, 2: infected B. velezensis XT1-treated plants 30 days after infection, 3: infected B. velezensis XT1-treated plants 90 days after infection, 4: molecular weight ladder. (b) Polyphenol oxidase (PPO) activity. Leaves of infected non-treated olive trees were used as control. (c) Incidence rate of infected non-treated control and infected XT1-treated olive trees. (d) Percentage of severity of infected non-treated control and infected XT1-treated olive trees. (e) Transversal cut of infected non-treated control and infected XT1-treated olive tree branches. (f) Whole plant aspect of infected non-treated control and infected XT1-treated trees. Significant differences with the control are indicated by asterisks $(* *, p<0.01$; $* * *, p<0.001)$.

\subsection{Reduction in Verticillium Wilt by B. velezensis XT1 on Diseased Olive Trees}

The effect of the palliative treatment with B. velezensis XT1 on adult ( 10-year old) diseased olive trees was evaluated in a field experiment in a naturally infected soil. Plant infection by $V$. dahliae was confirmed by isolating the fungi from affected areas on PDA and by microscopic observation (Figure 4a). The number of microsclerotia of Verticillium was determined to be 300 microsclerotia $\mathrm{g}^{-1}$ soil. At the beginning of the assay, symptom severity of the olive trees was $\sim 1.6$, according to the $0-4$ rating scale. Fourteen months after the treatment with B. velezensis XT1, symptom severity was significantly $(p<0.05)$ reduced by $\sim 63 \%$ in the olive trees treated with strain XT1 (Table 1 ). Differences could easily be assessed by visual inspection (Figure $4 b$ ). 
Table 1. Symptom Severity in the Palliative Treatment of Verticillium Wilt on Adult Diseased Trees with B. velezensis XT1.

\begin{tabular}{ccc}
\hline Treatment & Before the Treatment & After 14 Months \\
\hline Control & $1.6 \pm 0.6^{\mathrm{a}}$ & $2.7 \pm 1.2^{\mathrm{a}}$ \\
B. velezensis XT1 & $1.6 \pm 0.6^{\mathrm{a}}$ & $1.0 \pm 0.9^{\mathrm{b}}$
\end{tabular}

Mean values within a column followed by different lowercase letters $\left({ }^{a},{ }^{b}\right)$ indicate that they are significantly different $(p \leq 0.05)$.

a

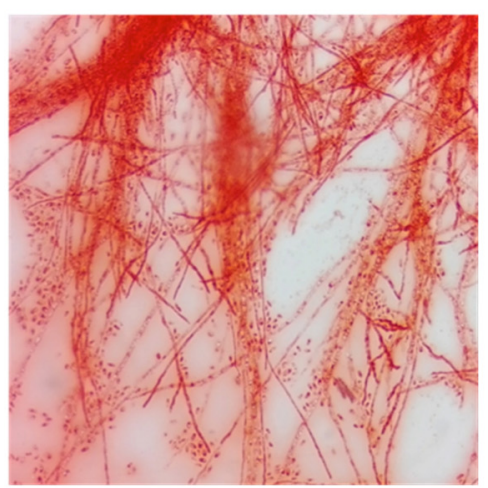

b

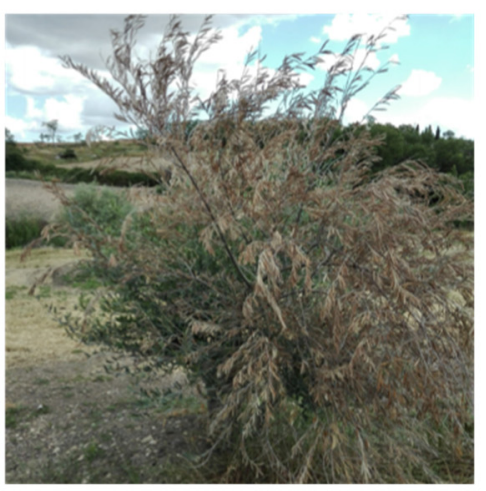

Diseased non-treated control

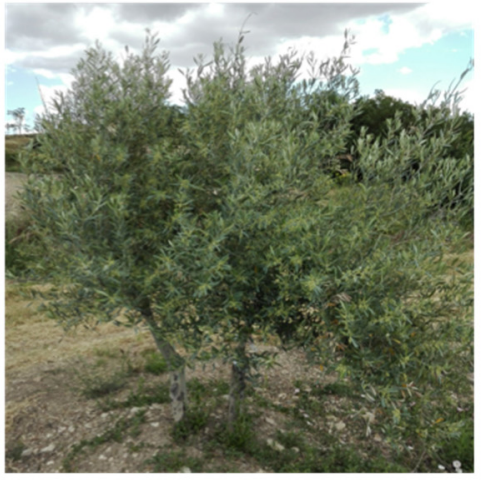

Diseased B. velezensis XT1-treated

Figure 4. Palliative treatment of Verticillium wilt on diseased adult olive trees by Bacillus velezensis XT1. (a) Microscopic observation of $V$. dahliae isolated from affected trees. (b) Olive trees in the field experiment before and after the treatment with strain XT1. Control consisted of diseased non-treated trees.

\subsection{Permanence of B. velezensis XT1 in Soil}

The permanence of $B$. velezensis XT1 in the soil after being inoculated in the olive trees was measured using a $\operatorname{Rif}^{R}$ XT1 strain. The results showed that the population of strain XT1 was maintained at an average count of $3.5 \times 10^{5} \mathrm{CFU} \mathrm{g}^{-1}$ of soil until 30 days after the inoculation, when it decreased to $5.9 \times 10^{4} \mathrm{CFU} \mathrm{g}^{-1}$ and was kept stable until the end of the experiment, 120 days later. No Rif ${ }^{\mathrm{R}}$ colonies could be recovered from the soil of the non-treated control olive trees.

\subsection{Endophytic Growth of B. velezensis XT1 in Olive Roots}

The ability of B. velezensis XT1 to grow endophytically on olive roots was tested using a Rif ${ }^{R}$ XT1 strain. One-hundred and twenty days after the inoculation of the olive trees with strain XT1, the average number of endophytic XT1 was reported as $3.5 \times 10^{4} \mathrm{CFU} \mathrm{g}^{-1}$ of fresh root. No Rif ${ }^{\mathrm{R}}$ clones were recovered in the non-treated control. 


\section{Discussion}

In the agriculture sector, Verticillium wilt is among the most devastating fungal diseases worldwide. It affects hundreds of different plant species, including high value agricultural crops such as olive trees [6]. A major issue that concerns Verticillium disease management [31] is increasing soil salinization. In recent years, novel eco-friendly strategies are being sought in order to control plant diseases and stimulate plant growth in such a soil salinity scenario [65], with the aim of rendering the agriculture industry more sustainable and keeping a healthy environment.

B. velezensis XT1, previously isolated from a rhizosphere sample taken from a saline soil $[0.6 \%$ $(w / v) \mathrm{NaCl}$, is a salt-tolerant biocontrol strain that has the ability to grow in a wide range of salt concentrations, from 0 to $12 \%(w / v) \mathrm{NaCl}$ [34]. Strain XT1 has been described to promote plant growth due to different metabolic features such as nitrogen-fixation, siderophore production or synthesis of enzymes [34]. One of these enzymes, the 1-aminocyclopropane-1-carboxylate (ACC) deaminase, is involved in increased disease tolerance against $V$. dahliae [66]. Despite the fact that some strains of the $B$. velezensis species have recently been described as biocontrol agents against Verticillium wilt on olive trees, such as B. velezensis OEE1 [30], the activity of different isolates may differ due to the existence of strain-specific clusters of genes, and consequently, due to the synthesis of special enzymes and metabolites which are involved in both pathogen suppression, growth promotion, and salt tolerance. Regarding the latter, we believe that this is a desirable trait in Verticillium biocontrol agents, but future experiments are needed to assess the effect of the salt-tolerant strain XT1 on $V$. dahliae under saline conditions. Soil salinity is an upcoming problem due to intensive agriculture and climate change, especially in Andalusia, South Spain [67], the world's largest producer of olive oil in the world [9]. According to Kaurichev [68], soils containing more than $0.2 \%(w / v)$ soluble salts should be considered as saline soils. Although olive trees are considered moderately tolerant to salinity [69], this abiotic stress leads to an increase in plant colonization and disease severity by $V$. dahliae [31,32] and affects the antagonist activity of some Verticillium biocontrol agents [33].

In this study, B. velezensis XT1 showed strong antifungal activity against the highly virulent defoliating $V$. dahliae V024. The activity in vitro was higher in liquid than in solid medium, which has also been observed against other phytopathogenic fungi, such as Botrytis cinerea [34,49]. Similar inhibition rates against $V$. dahliae were observed in plate assays with $B$. thuringiensis isolates [70] and a non-pathogenic strain of Fusarium oxysporum [25]. Regarding the antifungal activity of the supernatant, this indicates that the activity is due to extracellular metabolites and is not only contact-dependent. In this work, the undiluted and half-diluted supernatant of B. velezensis XT1 showed a strong antifungal activity against $V$. dahliae. For instance, the half-diluted supernatant reduced fungal mycelium by 91\%, while Azabou et al. [30] described that the half-diluted supernatant of B. velezensis OEE1 had an activity of $69 \%$. Some of the extracellular metabolites produced by bacteria are lipopeptides, biosurfactant molecules with activity against numerous plant pathogens [21], and volatile organic compounds [20]. Lipopeptides, apart from having antifungal activity, may be involved in inhibiting microsclerotia formation in $V$. dahliae, according to Yu et al. [71]. Strain XT1 was previously described to produce large amounts of heat-stable lipopeptides, which were identified by electrospray quadrupole time-of-flight mass spectrometry as four different types of surfactin, three bacillomycins D (iturin family), and fengycin A and B [49]. The exact composition of the crude lipopeptide extract of strain XT1 was not quantified, although in other B. velezensis strains, it was described to be $\sim 40 \mu \mathrm{g} \mathrm{mL} \mathrm{m}^{-1}$ of surfactin, $\sim 30 \mu \mathrm{g} \mathrm{mL}{ }^{-1}$ of iturin, and $\sim 140 \mu \mathrm{g} \mathrm{mL}^{-1}$ of fengycin [72]. In the case of B. velezensis OEE1, some lipopeptides have been identified by PCR amplification [30], although such detection method using specific primers does not imply production of the corresponding lipopeptide, as observed with iturin in strain XT1 [49]. In this study, the crude lipopeptide extract of strain XT1 reduced fungal growth by more than $80 \%$ at different concentrations. However, there are no data available regarding the activity of lipopeptide biosurfactants for B. velezensis OEE1 [30]. With regard to volatile compounds, they are well known for having antifungal activity, plant growth promoting activity, and inducing systemic resistance [73-75]. The volatile organic compounds of 
B. velezensis XT1 inhibited by $34 \%$ mycelium growth of $V$. dahliae, which is comparable to the $40 \%$ inhibition reported for B. velezensis OEE1 [30], although the experimental set up is not exactly the same. Further studies need to be conducted to characterize such volatile compounds in strain XT1.

An essential requisite for a microorganism to be applied in the field should be its biosafety [76]. Although many bacterial strains have been proposed as biocontrol and/or plant growth stimulants in the last decade, their toxicity has not been tested. In this study, we have evaluated the biosafety of B. velezensis XT1 using a series of experiments proposed by Vílchez et al. [37]. Two tests were used to assess the impact on other microbial communities. In the test on E. coli MC4100, strain XT1 showed an antagonistic effect, although its effect was lower in comparison to the biocontrol B. cepacia CC-Al74 and to copper sulfate, used as a fungicide in agriculture settings. In the test Microtox assay, the supernatant of strain XT1 did not reduce the luminescence of $A$. fischeri NRRL B-11177, and the EC50 was reached with a solution in distilled water with $90 \%(v / v)$ of culture supernatant, meaning an absence of toxicity of strain XT1 [40]. Finally, the impact of XT1 on the survival of soil nematodes was evaluated with a C. elegans $\mathrm{N} 2$ bioassay. It was observed that $B$. velezensis XT1 did not have a negative effect on the viability of the nematodes. Additionally, it was found that the effective concentration of XT1 used in the field was nine times smaller than its LC50, meaning very low toxicity. However, in the case of the chemical fungicide of frequent agricultural use, copper sulfate, its effective dose was superior to its LC50. All these data, together with the fact that the majority of environmental Bacillus species (such as B. subtilis and B. amyloliquefaciens) belong to biosafety level 1 category, reflect that strain XT1 is not toxic and can be used for formulation development and field scale applications [76]. Regarding the other $B$. velezensis strain with activity against $V$. dahliae, strain OEE1, there are no available data concerning its biosafety, and a toxic and harmful effect is observed in plants when the inoculum of the strain is $10^{6}$ $\mathrm{CFU} \mathrm{g}^{-1}[30]$.

Although not a requisite, some desirable characteristics of biological control agents are plant growth promotion, the ability to deal with adverse environmental conditions, persistence in soil for long periods, and the capacity to colonize endophytically plant roots. In a previous work, we showed that B. velezensis XT1 promoted growth of different plant species [34]. Moreover, XT1 has shown to be highly resistant to adverse environmental conditions such as salinity, temperature or $\mathrm{pH}$, and to produce spores [34], which allow bacterial survival for long periods in stress conditions [77]. Regarding the persistence in soil, the rifampicin-resistant derivative of strain XT1 was found at high density several months after inoculation. Our results agree with the data obtained by Young [78] on $B$. cereus persistence. No data regarding the monitoring of the permanence of the inoculum on soil were published for $B$. velezensis OEE1 [30]. With respect to the ability to effectively colonize endophytically plant roots, it could play an important role in the biocontrol effectiveness of strain XT1, which was also observed in B. velezensis OEE1 [30] and in P. fluorescens PICF7 [79]. However, these results must be interpreted cautiously, since a $\operatorname{Rif}^{\mathrm{R}}$ XT1 strain was used instead of the wild type. Rifampicin resistance is commonly used as a reliable marker to study plant colonization by Bacillus spp. and other soil bacteria [80-84]. Despite the fact that pleiotropic effects have recently been observed in a Bacillus velezensis rifampicin-resistant mutant strain [85], population dynamics of wild-type and antibiotic-resistant derivatives were observed to be similar in other Bacillus species [82].

Once the antifungal activity in vitro, biosafety, and other desirable traits of B. velezensis XT1 were determined, we evaluated its use as a preventive measure (treatment before infection occurs) and palliative action (application after infection) on olive trees infected with $V$. dahliae. For the preventive treatment, olive plants were infected using a root-dip inoculation method with $V$. dahliae conidiospores, as used by other authors $[2,54,55]$. However, alternative infection methods have recently been proposed, since root-dip inoculation make it difficult to assess the effect of biocontrol agents due to the high inoculum pressure of the pathogen and the fact that, once the pathogen has colonized the plants, it is highly inaccessible to biocontrol agents [35]. For both preventive and palliative treatments, the Picual variety was used for the experiments for being the most produced in Spain and one of the varieties most affected by Verticillium [86,87]. 
In the preventive treatment on young olive trees, $B$. velezensis XT1 reduced the percentage of severity by $\sim 80 \%$. This is very superior to the $\sim 47 \%$ reduction obtained by P. alvei K165 [27] and similar to the results obtained with $B$. velezensis OEE1 [30]. However, the plant system used by the latter was seedlings grown in modified solid medium [88] during a short period, instead of olive trees in pots with soil substrate and maintained during long incubation periods. Additionally, it is not clear if the Verticillum isolate used by Azabou et al. [30] is highly virulent and defoliating, as is the case of $V$. dahliae V024, and the conidiospore suspension they use to infect their plants is only $10^{4}$ conidiospores $\mathrm{mL}^{-1}$, while in our study, it is of $10^{7}$ conidiospores $\mathrm{mL}^{-1}$. Regarding the incidence rate, strain XT1 reduced by $54 \%$ this parameter. This percentage of reduction is higher than the values obtained by Cabanás et al. [89], Mulero-Aparicio et al. [90], and Varo et al. [91] with Pseudomonas spp., Fusarium oxysporum, and Bacillus spp., respectively, on infected olive trees. Regarding the number of microsclerotia in the upper layer of the soil [92], it was reduced by $\sim 20.2 \%$ after the addition of strain XT1. This leads to the belief that the antifungal activity of XT1 is more due to its interaction with the plant than from its activity in the soil. Varo et al. [91] obtained higher percentages of microsclerotia reduction, but the inoculum of the fungi and the Bacillus biocontrol organisms were considerably lower and higher, respectively. With regard to the detection of $V$. dahliae by PCR in the infected trees, the treatment with $B$. velezensis XT1 seemed to diminish the presence of the fungus in the plant. Although our PCR results are not quantitative, a reduction in the amount of PCR products could indicate a decrease in the pathogen within the infected plant, as observed by other authors [93,94]. In order to give a more accurate indication on the delay of infection and the quantification of Verticillium biomass within the plant tissue, this should be confirmed in further studies with quantitative techniques such as qPCR [95], even though these fail to discriminate between DNA from viable and dead fungal structures [96]. Regarding the evaluation of the stress caused by the infection on the olive trees, PPO activity is a parameter related with the content of phenolic compounds, which are metabolites that play different roles in plants, such as disease resistance [97]. If these compounds are not enough to stop pathogenic infection, they increase in the infection site and act as substrates to PPO enzymes, which catalyze the conversion of phenolic compounds into o-quinones, that are highly toxic for phytopathogens [98]. We found that the addition of strain XT1 increased PPO in comparison to the control, which indicates a higher resistance towards the infection [99]. Recently, some Streptomyces isolates showed the ability to increase PPO in leaves of cotton plants inoculated with V. dahliae [100], although the parameters were measured only three days after infection in plants cultured in vitro, and not in vivo as in our study. Unfortunately, the plant response to stress caused by the infection was not described in the other B. velezensis strains used against Verticillium wilt, such as strain OEE1, and therefore, comparison of the results is not possible [30].

Ultimately, the antifungal activity of $B$. velezensis XT1 was evaluated in the field as a palliative measure on adult olive trees that showed Verticillium wilt symptoms (symptom severity 1.6). The presence of $V$. dahliae was determined by the count of microsclerotia in the soil, the isolation of the fungi from diseased plant tissues, and the observation by microscopy of the fungi typical features. The palliative treatment with strain XT1 considerably reduced the severity of the symptoms by $\sim 63 \%$. Management of Verticillium wilt in woody long-lived plants has been investigated to a reduced extent. To date, biological control experiments on olive trees are very scarce. Azabou et al. [30] recently conducted a field experiment in a naturally infected soil with a content of $\sim 98$ microsclerotia $\mathrm{g}^{-1}$ soil, while in our case, there were 300 microsclerotia $\mathrm{g}^{-1}$ soil, but the experimental set up is not clearly explained to allow comparison. In addition, Mulero-Aparicio et al. [90] have recently tested several biocontrol agents under field conditions. Although the characteristics of the experiments are not the same as in our study, some comparison can be performed. For instance, $P$. fluorescens PICF04 did not reduce symptom severity of infected adult olive trees, while a mix of bacterial species (Rhodopseudomonas palustris, Rhodobacter sphacrodes, Lactobacillus plantarum, L. casei, Streptococcus lactis, Saccharomyces spp., and Streptomyces spp.) only reduced the disease severity by $30 \%$. These results are lower than those observed in our study with $B$. velezensis XT1. Nevertheless, more studies need 
to be conducted in the future to this end in order to evaluate if the initial symptom severity state of the diseased trees could have an impact on the effect with strain XT1.

\section{Conclusions}

The salt-tolerant $B$. velezensis XT1 shows strong antifungal activity against the highly virulent defoliating pathogen $V$. dahliae V024, which was demonstrated in vitro as well as on olive trees in greenhouse and field experiments with both preventive and palliative treatments. This, in addition to other characteristics of strain XT1 such as biosafety, enhancement of plant response to stress, persistence in soil, endophytic colonization of olive tree roots, and reduction of fungal microsclerotia in soil make it a promising biocontrol agent to be used against Verticillium wilt in the agriculture industry.

Author Contributions: D.C. performed the lab and greenhouse experiments and analyzed the data. B.T. and D.C. conducted the experiments in the field. I.S., F.M.-C. and V.B. conceived and designed the experimental techniques. V.B. supervised the study. M.T. prepared the figures and wrote the manuscript. All authors have read and agreed to the published version of the manuscript.

Funding: This research was funded by Xtrem Biotech S.L, the European Union SME Instrument (project XTOnE-774657) and the Spanish Ministries of Economy and Competitiveness (project SNEO-20161037E), Science and Innovation (project CGL2011-25748), Industry, Trade and Tourism (project VertiSOLUTION). IC was supported by a Ramón y Cajal program (RYC-2014-15532) from the Ministry of Economy and Competitiveness. DC was supported by a CEI-BioTic grant (CAEP2-46) of the BioTic Campus of International Excellence and an Industrial Doctorate contract (DI-14-06868) from the Ministry of Economy and Competitiveness.

Conflicts of Interest: DC was a full-time employee of Xtrem Biotech S.L., company that holds an exclusive license agreement on the patent that protects B. velezensis XT1 industrial explotation. All the authors declare that the research was conducted in the absence of any competing interests.

\section{References}

1. Ruggieri, G. A new disease of olive. L'Italia Agric. 1946, 83, 369-372.

2. Klosterman, S.J.; Atallah, Z.K.; Vallad, G.E.; Subbarao, K.V. Diversity, pathogenicity and management of Verticillium species. Annu. Rev. Phytopathol. 2009, 47, 39-62. [CrossRef] [PubMed]

3. Keykhasaber, M.; Thomma, B.P.H.J.; Hiemstra, J.A. Verticillium wilt caused by Verticillium dahliae in woody plants with emphasis on olive and shade trees. Eur. J. Plant Pathol. 2018, 150, 21-37. [CrossRef]

4. Berlanger, I.; Powelson, M.L. Verticillium wilt. Plant Heal. Instr. 2000. [CrossRef]

5. Landa, B.B.; Pérez, A.G.; Luaces, P.; Montes-Borrego, M.; Navas-Cortés, J.A.; Sanz, C. Insights into the effect of Verticillium dahliae defoliating-pathotype infection on the content of phenolic and volatile compounds related to the sensory properties of virgin olive oil. Front. Plant Sci. 2019, 10, 1-12. [CrossRef]

6. López-Escudero, F.J; Mercado-Blanco, J. Verticillium wilt of olive: A case study to implement an integrated strategy to control a soil-borne pathogen. Plant Soil 2011, 344, 1-50. [CrossRef]

7. Jiménez-Díaz, R.; Cirulli, M.; Bubici, G.; Jiménez-Gasco, M.; Antoniou, P.; Tjamos, E. Olive, an ancient crop under a major health threat Verticillium wilt on olive: Importance and distribution. Am. Phytopathol. Soc. Plant Dis. 2012, 96, 304-329. [CrossRef]

8. Food and Agriculture Organization of the United Nations (FAO). FAOSTAT database, Crops Processed, Data for Olive Oil; FAO: Italy, Rome, 2014.

9. Ministerio de Agricultura, Alimentación y Medio Ambiente (MAGRAMA). Avances de Superficies y Producciones de Cultivos: Spain. 2015. Available online: https:/www.mapa.gob.es/es/estadistica/temas/ estadisticas-agrarias/agricultura/avances-superficies-producciones-agricolas/2012-2015.aspx (accessed on 10 July 2020).

10. López-Escudero, F.J.; Mercado-Blanco, J.; Roca, J.M.; Valverde-Corredor, A.; Blanco-López, M.A. Verticillium wilt of olive in the Guadalquivir valley (southern Spain): Relations with some agronomical factors and spread of Verticillium dahliae. Phytopathol. Mediterr. 2010, 49, 370-380. [CrossRef]

11. Prieto, P.; Navarro-Raya, C.; Valverde-Corredor, A.; Amyotte, S.G.; Dobinson, K.F.; Mercado-Blanco, J. Colonization process of olive tissues by Verticillium dahliae and its in planta interaction with the biocontrol root endophyte Pseudomonas fluorescens PICF7. Microb. Biotechnol. 2009, 2, 499-511. [CrossRef] [PubMed] 
12. Fradin, E.; Thomma, B. Physiology and molecular aspects of Verticillium wilt diseases caused by V. dahliae and V. albo-atrum. Mol. Plant Pathol. 2006, 7, 71-86. [CrossRef] [PubMed]

13. Tjamos, E.; Botseas, D. Occurrence of Verticillium dahliae in leaves of Verticillium-wilted olive trees. Can. J. Plant Pathol. 1987, 9, 86.

14. Hiemstra, J. Some general features of Verticillium wilts in trees. In A Compendium of Verticillium Wilts in Tree Species.; Hiemstra, J., Harris, D., Eds.; Ponsen and Looijen: Wageningen, The Netherlands, 1998; pp. 5-11.

15. Tjamos, E. Prospects and strategies in controlling Verticillium wilt of olive. EPPO Bull. 1993, 23, 505-512. [CrossRef]

16. Mercado-Blanco, J.; Rodríguez-Jurado, D.; Hervás, A.; Jiménez-Díaz, R.M. Suppression of Verticillium wilt in olive planting stocks by root-associated fluorescent Pseudomonas spp. Biol. Control 2004, 30, 474-486. [CrossRef]

17. Colla, P.; Gilardi, G.; Gullino, M.L. A review and critical analysis of the European situation of soilborne disease management in the vegetable sector. Phytoparasitica 2012, 40, 515-523. [CrossRef]

18. Richardson, A.E.; Barea, J.-M.; McNeill, A.M.; Prigent-Combaret, C. Acquisition of phosphorus and nitrogen in the rhizosphere and plant growth promotion by microorganisms. Plant Soil 2009, 321, 305-339. [CrossRef]

19. Borriss, R. Use of Plant-Associated Bacillus Strains as Biofertilizers and Biocontrol Agents in Agriculture. In Bacteria in Agrobiology: Plant Growth Responses; Springer: Berlin, Germany, 2011; pp. 41-76.

20. Ryu, C.; Farag, M.A.; Hu, C.; Reddy, M.S.; Kloepper, J.W.; Pare, P.W. Bacterial volatiles induced resistance in Arabidobsis. Plant Physiol. 2004, 134, 1017-1026. [CrossRef]

21. Ongena, M.; Jacques, P. Bacillus lipopeptides: Versatile weapons for plant disease biocontrol. Trends Microbiol. 2008, 16, 115-125. [CrossRef]

22. Wei, G. Induction of systemic resistance of cucumber to Colletotrichum orbiculare by select strains of plant growth-promoting rhizobacteria. Phytopathology 1991, 81, 1508. [CrossRef]

23. Deketelaere, S.; Tyvaert, L.; França, S.C.; Hofte, M. Desirable traits of a good biocontrol agent against Verticillium wilt. Front. Microbiol. 2017, 8, 1-23. [CrossRef]

24. Carrero-Carrón, I.; Trapero-Casas, J.L.; Olivares-García, C.; Monte, E.; Hermosa, R.; Jiménez-Díaz, R.M. Trichoderma asperellum is effective for biocontrol of Verticillium wilt in olive caused by the defoliating pathotype of Verticillium dahliae. Crop Prot. 2016, 88, 45-52. [CrossRef]

25. Mulero-Aparicio, A.; Agustí-Brisach, C.; Varo, Á.; López-Escudero, F.J.; Trapero, A. A non-pathogenic strain of Fusarium oxysporum as a potential biocontrol agent against Verticillium wilt of olive. Biol. Control 2019, 139, 104045. [CrossRef]

26. Müller, H.; Westendorf, C.; Leitner, E.; Chernin, L.; Riedel, K.; Schmidt, S.; Eberl, L.; Berg, G. Quorum-sensing effects in the antagonistic rhizosphere bacterium Serratia plymuthica HRO-C48. FEMS Microbiol. Ecol. 2009, 67, 468-478. [CrossRef] [PubMed]

27. Markakis, E.A.; Tjamos, S.E.; Antoniou, P.P.; Paplomatas, E.J.; Tjamos, E.C. Biological control of Verticillium wilt of olive by Paenibacillus alvei, strain K165. BioControl 2016, 61, 293-303. [CrossRef]

28. Maldonado-González, M.M.; Bakker, P.A.H.M.; Prieto, P.; Mercado-Blanco, J. Arabidopsis thaliana as a tool to identify traits involved in Verticillium dahliae biocontrol by the olive root endophyte Pseudomonas fluorescens PICF7. Front. Microbiol. 2015, 6, 1-12. [CrossRef]

29. Li, S.; Zhang, N.; Zhang, Z.; Luo, J.; Shen, B.; Zhang, R.; Shen, Q. Antagonist Bacillus subtilis HJ5 controls Verticillium wilt of cotton by root colonization and biofilm formation. Biol. Fertil. Soils 2013, 49, $295-303$. [CrossRef]

30. Azabou, M.C.; Gharbi, Y.; Medhioub, I.; Ennouri, K.; Barham, H.; Tounsi, S.; Triki, M.A. The endophytic strain Bacillus velezensis OEE1: An efficient biocontrol agent against Verticillium wilt of olive and a potential plant growth promoting bacteria. Biol. Control 2020, 142, 104168. [CrossRef]

31. Levin, A.G.; Lavee, S.; Tsror (Lahkim), L. The influence of salinity on Verticillium dahliae in stem cuttings of five olive cultivars. J. Phytopathol. 2007, 155, 587-592. [CrossRef]

32. Saadatmand, A.R.; Banihashemi, Z.; Sepaskhah, A.R.; Maftoun, M. Soil salinity and water stress and their effect on susceptibility to Verticillium wilt disease, ion composition and growth of pistachio. J. Phytopathol. 2008, 156, 287-292. [CrossRef]

33. Regragui, A.; Lahlou, H. Effect of salinity on in vitro Trichoderma harzianum antagonism against Verticillium dahliae. Pakistan J. Biol. Sci. 2005, 8, 872-876. [CrossRef] 
34. Torres, M.; Llamas, I.; Torres, B.; Toral, L.; Sampedro, I.; Béjar, V. Growth promotion on horticultural crops and antifungal activity of Bacillus velezensis XT1. Appl. Soil Ecol. 2020, 150, 103453. [CrossRef]

35. Varo, A.; Moral, J.; Lozano-Tóvar, M.D.; Trapero, A. Development and validation of an inoculation method to assess the efficacy of biological treatments against Verticillium wilt in olive trees. BioControl 2016, 61, 283-292. [CrossRef]

36. Stiernagle, T. Maintenance of Caenorhabditis elegans. In Wormbook: The Online Review of C. elegans Biology; WormBook: Pasadena, CA, USA, 2006; pp. 1-11.

37. Vílchez, J.I.; Navas, A.; González-lópez, J.; Arcos, S.C.; Gutierrez, F.J. Biosafety test for plant growth-promoting bacteria: Proposed environmental and human safety index (EHSI) protocol. Front. Microbiol. 2016, 6, 1514. [CrossRef]

38. Johnson, B. Microtox@acute toxicity test. In Small-Scale Freshwater Toxicity Investigations: Toxicity Test Methods; Blaise, C., Férard, J., Eds.; Springer: Dordrecht, The Netherlands, 2005; Volume 1, pp. 69-105. ISBN 140203119X.

39. Cooper, D.; MacDonald, C.; Duff, S.; Kosaric, N. Enhanced production of surfactin from Bacillus subtilis by continuous product removal and metal cations addition. Appli. Environ. Microbiol. 1981, 54, 224-229. [CrossRef]

40. Onorati, F.; Mecozzi, M. Effects of two diluents in the Microtox®toxicity bioassay with marine sediments. Chemosphere 2004, 54, 679-687. [CrossRef] [PubMed]

41. Darby, C.; Cosma, C.L.; Thomas, J.H.; Manoil, C. Lethal paralysis of Caenorhabditis elegans by Pseudomonas aeruginosa. Proc. Natl. Acad. Sci. USA 1999, 96, 15202-15207. [CrossRef] [PubMed]

42. Navas, A.; Cobas, G.; Talavera, M.; Ayala, J.A.; Lopez, J.A.; Martinez, J.L. Experimental validation of Haldane's hypothesis on the role of infection as an evolutionary force for Metazoans. Proc. Natl. Acad. Sci. USA 2007, 104, 13728-13731. [CrossRef] [PubMed]

43. Tan, M.; Mahajan-Miklos, S.; Ausubel, F. Killing of Caenorhabditis elegans by Pseudomonas aeruginosa used to model mammalian bacterial pathogenesis. Proc. Natl. Acad. Sci. USA 1999, 96, 715-720. [CrossRef] [PubMed]

44. Brenner, S. The genetics of Caenorhabditis elegans. Genetics 1974, 77, 71-94.

45. Williams, P.L.; Dusenbery, D.B. Using the nematode Caenorhabditis elegans to predict mammalian acute lethality to metallic salts. Toxicol. Ind. Health 1988, 4, 469-478. [CrossRef] [PubMed]

46. Boyd, W.A.; Smith, M.V.; Freedman, J.H. Caenorhabditis elegans as a model in developmental toxicology. Methods Mol. Biol. 2012, 889, 15-24. [CrossRef]

47. Schaeffer, P.; Millet, J.; Aubert, J.P. Catabolic repression of bacterial sporulation. Proc. Natl. Acad. Sci. USA 1965, 54, 704-711. [CrossRef]

48. Frikha-Gargouri, O.; Ben Abdallah, D.; Ghorbel, I.; Charfeddine, I.; Jlaiel, L.; Triki, M.; Tounsi, S. Lipopeptides from a novel Bacillus methylotrophicus 39b strain supress Agrobacterium crown gall tumours on tomato plants. Pest Manag. Sci. 2017, 73, 568-574. [CrossRef]

49. Toral, L.; Rodríguez, M.; Béjar, V.; Sampedro, I. Antifungal activity of lipopeptides from Bacillus XT1 CECT 8661 against Botrytis cinerea. Front. Microbiol. 2018, 9, 1315. [CrossRef]

50. Ji, S.H.; Paul, N.C.; Deng, J.X.; Kim, Y.S.; Yun, B.-S.; Yu, S.H. Biocontrol activity of Bacillus amyloliquefaciens CNU114001 against fungal plant diseases. Mycobiology 2013, 41, 234-242. [CrossRef] [PubMed]

51. Ahimou, F.; Jacques, P.; Deleu, M. Surfactin and iturin A effects on Bacillus subtilis surface hydrophobicity. Enzyme Microb. Technol. 2000, 27, 749-754. [CrossRef]

52. Schneider, C.; Rasband, W.; Eliceiri, K. NIH Image to ImageJ: 25 years of Image Analysis. Nat. Methods 2012, 9, 671-675. [CrossRef] [PubMed]

53. Yazgan, A.; Özcengiz, G.; Marahiel, M.A. Tn10 insertional mutations of Bacillus subtilis that block the biosynthesis of bacilysin. Biochim. Biophys. Acta Gene Struct. Expr. 2001, 1518, 87-94. [CrossRef]

54. Colella, C.; Miacola, C.; Amenduni, M.; D’Amico, M.; Bubici, G.; Cirulli, M. Sources of Verticillium wilt resistance in wild olive germplasm from the Mediterranean region. Plant Pathol. 2008, 57, 533-539. [CrossRef]

55. Trapero, C.; Díez, C.M.; Rallo, L.; Barranco, D.; López-Escudero, F.J. Effective inoculation methods to screen for resistance to Verticillium wilt in olive. Sci. Hortic. 2013, 162, 252-259. [CrossRef]

56. Doyle, J.; Doyle, J. A rapid total DNA preparation procedure for fresh plant tissue. Focus 1990, 12, 13-15. 
57. Carder, J.; Morton, A.; Tabrett, A.; Barbara, D. Detection and differentiation by PCR of subspecific groups within two Verticillium species causing vascular wilts in herbaceous hosts. In Modern Assays for plant pathogenic Fungi: Identification, detection and quantification; Schots, A., Dewey, F., Oliver, R., Eds.; CAB International: Oxford, UK, 1994; pp. 91-97.

58. Aquino-Bolaños, E.N.; Mercado-Silva, E. Effects of polyphenol oxidase and peroxidase activity, phenolics and lignin content on the browning of cut jicama. Postharvest Biol. Technol. 2004, 33, 275-283. [CrossRef]

59. López-Escudero, F.J.; Del Río, C.; Caballero, J.M.; Blanco-López, M.A. Evaluation of olive cultivars for resistance to Verticillium dahliae. Eur. J. Plant Pathol. 2004, 110, 79-85. [CrossRef]

60. Kabir, Z.; Bhat, R.G.; Subbarao, K.V. Comparison of media for recovery of Verticillium dahliae from soil. Plant Dis. 2004, 88, 49-55. [CrossRef]

61. Kapulnik, E.; Quick, J.; DeVay, J. Germination of propagules of Verticillium dahliae in soil treated with methionine and other substances affecting ethylene production. Phytopathology 1975, 75, 1348.

62. Bandoni, R. Safranin O as a rapid nuclear stain for fungi. Mycologia 1979, 11, 873-874. [CrossRef]

63. Food and Agriculture Organization of the United Nations (FAO). Soil Map of the World. Revised Legend, by FAO-UNESCO-ISRIC. World Soil Resour. Rep. 1988, 84, 21-22.

64. Team R.C., R. A Language and Environment for Statistical Computing; R Foundation for Statistical Computing: Vienna, Austria, 2007.

65. Shrivastava, P.; Kumar, R. Soil salinity: A serious environmental issue and plant growth promoting bacteria as one of the tools for its alleviation. Saudi J. Biol. Sci. 2015, 22, 123-131. [CrossRef]

66. Robison, M.M.; Shah, S.; Tamot, B.; Pauls, K.P.; Moffatt, B.A.; Glick, B.R. Reduced symptoms of Verticillium wilt in transgenic tomato expressing a bacterial ACC deaminase. Mol. Plant Pathol. 2001, 2, $135-145$. [CrossRef]

67. Hamidov, A.; Helming, K.; Bellocchi, G.; Bojar, W.; Dalgaard, T.; Ghaley, B.B.; Hoffmann, C.; Holman, I.; Holzkämper, A.; Krzeminska, D.; et al. Impacts of climate change adaptation options on soil functions: A review of European case-studies. L. Degrad. Dev. 2018, 29, 2378-2389. [CrossRef]

68. Kaurichev, I. Prácticas de Edafologia, 1st ed.; Mir Publishers: Moscow, Russia, 1980.

69. Maas, E.; Hoffman, G. Crop salt tolerance-current assessment. J. Irrig. Drain. Div. 1977, 103, 115-134.

70. Hollensteiner, J.; Wemheuer, F.; Harting, R.; Kolarzyk, A.M.; Diaz Valerio, S.M.; Poehlein, A.; Brzuszkiewicz, E.B.; Nesemann, K.; Braus-Stromeyer, S.A.; Braus, G.H.; et al. Bacillus thuringiensis and Bacillus weihenstephanensis inhibit the growth of phytopathogenic Verticillium species. Front. Microbiol. 2017, 7, 2171. [CrossRef] [PubMed]

71. Yu, D.; Fang, Y.; Tang, C.; Klosterman, S.J.; Tian, C.; Wang, Y. Genomewide transcriptome profiles reveal how Bacillus subtilis lipopeptides inhibit microsclerotia formation in Verticillium dahliae. Mol. Plant-Microbe Interact. 2019, 32, 622-634. [CrossRef]

72. Cao, Y.; Pi, H.; Chandrangsu, P.; Li, Y.; Wang, Y.; Zhou, H.; Xiong, H.; Helmann, J.D.; Cai, Y. Antagonism of two plant-growth promoting Bacillus velezensis isolates against Ralstonia solanacearum and Fusarium oxysporum. Sci. Rep. 2018, 8, 4360. [CrossRef]

73. Audrain, B.; Farag, M.A.; Ryu, C.-M.; Ghigo, J.-M. Role of bacterial volatile compounds in bacterial biology. FEMS Microbiol. Rev. 2015, 39, 222-233. [CrossRef] [PubMed]

74. Fernando, W.G.D.; Ramarathnam, R.; Krishnamoorthy, A.S.; Savchuk, S.C. Identification and use of potential bacterial organic antifungal volatiles in biocontrol. Soil Biol. Biochem. 2005, 37, 955-964. [CrossRef]

75. Mulero-Aparicio, A.; Cernava, T.; Turrà, D.; Schaefer, A.; Di Pietro, A.; López-Escudero, F.J.; Trapero, A.; Berg, G. The role of volatile organic compounds and rhizosphere competence in mode of action of the non-pathogenic Fusarium oxysporum FO12 toward Verticillium wilt. Front. Microbiol. 2019, 10, 1808. [CrossRef]

76. Keswani, C.; Prakash, O.; Bharti, N.; Vílchez, J.I.; Sansinenea, E.; Lally, R.D.; Borriss, R.; Singh, S.P.; Gupta, V.K.; Fraceto, L.F.; et al. Re-addressing the biosafety issues of plant growth promoting rhizobacteria. Sci. Total Environ. 2019, 690, 841-852. [CrossRef]

77. Checinska, A.; Paszczynski, A.; Burbank, M. Bacillus and other spore-forming genera: Variations in responses and mechanisms for survival. Annu. Rev. Food Sci. Technol. 2015, 6, 351-369. [CrossRef]

78. Young, C. Survival of inoculated Bacillus cereus spores and vegetative cells in non-planted and rhizosphere soil. Soil Biol. Biochem. 1995, 27, 1017-1026. [CrossRef] 
79. Prieto, P.; Mercado-Blanco, J. Endophytic colonization of olive roots by the biocontrol strain Pseudomonas fluorescens PICF7. FEMS Microbiol. Ecol. 2008, 64, 297-306. [CrossRef]

80. Yan, Z.; Reddy, M.S.; Kloepper, J.W. Survival and colonization of rhizobacteria in a tomato transplant system. Can. J. Microbiol. 2003, 49, 383-389. [CrossRef]

81. Coy, R.M.; Held, D.W.; Kloepper, J.W. Rhizobacterial colonization of bermudagrass by Bacillus spp. in a Marvyn loamy sand soil. Appl. Soil Ecol. 2019, 141, 10-17. [CrossRef]

82. Mendis, H.C.; Thomas, V.P.; Schwientek, P.; Salamzade, R.; Chien, J.-T.; Waidyarathne, P.; Kloepper, J.; De La Fuente, L. Strain-specific quantification of root colonization by plant growth promoting rhizobacteria Bacillus firmus I-1582 and Bacillus amyloliquefaciens QST713 in non-sterile soil and field conditions. PLoS ONE 2018, 13, e0193119. [CrossRef] [PubMed]

83. Glandorf, D.C.M.; Brand, I.; Bakker, P.A.H.M.; Schippers, B. Stability of rifampicin resistance as a marker for root colonization studies of Pseudomonas putida in the field. Plant Soil 1992, 147, 135-142. [CrossRef]

84. Xu, J.-X.; Li, Z.-Y.; Lv, X.; Yan, H.; Zhou, G.-Y.; Cao, L.-X.; Yang, Q.; He, Y.-H. Isolation and characterization of Bacillus subtilis strain 1-L-29, an endophytic bacteria from Camellia oleifera with antimicrobial activity and efficient plant-root colonization. PLoS ONE 2020, 15, e0232096. [CrossRef] [PubMed]

85. Cai, X.-C.; Xi, H.; Liang, L.; Liu, J.-D.; Liu, C.-H.; Xue, Y.-R.; Yu, X.-Y. Rifampicin-resistance mutations in the rpoB gene in Bacillus velezensis CC09 have pleiotropic effects. Front. Microbiol. 2017, 8, 178. [CrossRef]

86. Martos-Moreno, C.; López-Escudero, F.J.; Blanco-López, M.A. Resistance of olive cultivars to the defoliating pathotype of Verticillium dahliae. HortScience 2006, 41, 1313-1316. [CrossRef]

87. Trapero, C.; Rallo, L.; López-Escudero, F.J.; Barranco, D.; Díez, C.M. Variability and selection of Verticillium wilt resistant genotypes in cultivated olive and in the Olea genus. Plant Pathol. 2015, 64, 890-900. [CrossRef]

88. Murashige, T.; Skoog, F. A revised medium for rapid growth and bio assays with tobacco tissue cultures. Physiol. Plant. 1962, 15, 473-497. [CrossRef]

89. Cabanás, C.G.L.; Legarda, G.; Ruano-Rosa, D.; Pizarro-Tobías, P.; Valverde-Corredor, A.; Niqui, J.L.; Triviño, J.C.; Roca, A.; Mercado-Blanco, J. Indigenous Pseudomonas spp. strains from the olive (Olea europaea L.) rhizosphere as effective biocontrol agents against Verticillium dahliae: From the host roots to the bacterial genomes. Front. Microbiol. 2018, 9, 227. [CrossRef]

90. Mulero-Aparicio, A.; Varo, A.; Agustí-Brisach, C.; López-Escudero, F.J.; Trapero, A. Biological control of Verticillium wilt of olive in the field. Crop Prot. 2020, 128, 104993. [CrossRef]

91. Varo, A.; Raya-Ortega, M.C.; Trapero, A. Selection and evaluation of micro-organisms for biocontrol of Verticillium dahliae in olive. J. Appl. Microbiol. 2016, 121, 767-777. [CrossRef] [PubMed]

92. Short, D.P.G.; Sandoya, G.; Vallad, G.E.; Koike, S.T.; Xiao, C.-L.; Wu, B.-M.; Gurung, S.; Hayes, R.J.; Subbarao, K.V. Dynamics of Verticillium species microsclerotia in field soils in response to fumigation, cropping patterns and flooding. Phytopathology 2015, 105, 638-645. [CrossRef] [PubMed]

93. Rodriguez-Jurado, D. Interacciones huesped-parasito en la Verticilosis del olivo (Olea europaea L.) inducida por Verticillium dahliae Kleb. Ph.D., Thesis, University of Cordoba, Cordoba, Spain, 1993.

94. Mercado-Blanco, J.; Rodriguez-Jurado, D.; Perez-Artes, E.; Jimenez-Diaz, R. Detection of the defoliating pathotype of Verticillium dahliae in infected olive plants by nested PCR. Eur. J. Plant Pathol. 2002, 108, 1-13. [CrossRef]

95. Mercado-Blanco, J.; Collado-Romero, M.; Parrilla-Araujo, S.; Rodríguez-Jurado, D.; Jiménez-Díaz, R.M. Quantitative monitoring of colonization of olive genotypes by Verticillium dahliae pathotypes with real-time polymerase chain reaction. Physiol. Mol. Plant Pathol. 2003, 63, 91-105. [CrossRef]

96. Tzelepis, G.; Bejai, S.; Sattar, M.N.; Schwelm, A.; Ilbäck, J.; Fogelqvist, J.; Dixelius, C. Detection of Verticillium species in Swedish soils using real-time PCR. Arch. Microbiol. 2017, 199, 1383-1389. [CrossRef]

97. Nicholson, R.L.; Hammerschmidt, R. Phenolic compounds and their role in disease resistance. Annu. Rev. Phytopathol. 1992, 30, 369-389. [CrossRef]

98. Lattanzio, V.; Lattanzio, V.; Cardinali, A. Role of phenolics in the resistance mechanisms of plants against fungal pathogens and insects. Phytochemistry 2006, 661, 23-67. 
99. Agrios, G. Plant Pathology; Elsevier Academic Press: Amsterdam, The Netherlands, 2005.

100. Xue, L.; Gu, M.-Y.; Xu, W.-L.; Lu, J.-J.; Xue, Q.-H. Antagonistic Streptomyces enhances defense-related responses in cotton for biocontrol of wilt caused by phytotoxin of Verticillium dahliae. Phytoparasitica 2016, 44, 225-237. [CrossRef]

(c)

(C) 2020 by the authors. Licensee MDPI, Basel, Switzerland. This article is an open access article distributed under the terms and conditions of the Creative Commons Attribution (CC BY) license (http://creativecommons.org/licenses/by/4.0/). 